DOT/FAA/AM-97/3

Office of Aviation Medicine

XIashington, D.C. 20591

\section{The Use of Weather Information in Aeronautical Decision-Making}

Walter E. Driskill

Johnny J. Weissmuller

John Quebe

Darryl K. Hand

Martin J. Dittmar

Metrica, Inc.

San Antoris', Texas

David R. Hunter

Office of Aviation Medicine

Federal Aviation Administration

Washington, DC 20591

February 1997

Final Report

This do ment is available to the public through the National Technical Information Service, Springfield, Virginia 22161.

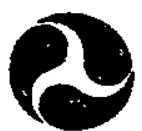

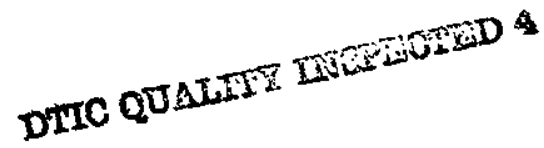

U.S. Department of Transportation

Federal Aviation Administration 


\section{NOTICE}

This document is disseminated under the sponsorship of the U.S. Department of Transportation in the interest of information exchange. The United States Government assumes no liability for the contents or use thereof. 
Technical Report Documentation Page

\begin{tabular}{|c|c|c|}
\hline $\begin{array}{l}\text { 1. Report No. } \\
\text { DOT/FAA/AM-97/3 }\end{array}$ & 2. Goveroment Accession No. & 3. Recipient's Catalog No. \\
\hline \multirow{2}{*}{\multicolumn{2}{|c|}{$\begin{array}{l}\text { 4. Thite and Subtitie } \\
\text { The Use of Weather Information in Aeronautical Decision-Making }\end{array}$}} & $\begin{array}{l}\text { 5. Repont Date } \\
\text { February } 1997\end{array}$ \\
\hline & & 6. Performirg Organization Code \\
\hline \multicolumn{2}{|c|}{$\begin{array}{l}\text { 7. Author(s) } \\
\text { W.E. Driskill, J.J. Weissmuller, J. Quebe, D.K. Hand, M.J. Dittmar, } \\
\text { (Metrica, Inc.), and D.R. Hunter, (FAA). }\end{array}$} & 8. Performing Organization Report No. \\
\hline \multicolumn{2}{|c|}{ 9. Performing Organization Name and Address } & 10. Work Unit No. (TRAIS) \\
\hline \multirow{2}{*}{$\begin{array}{l}\text { Metrica, Inc. } \\
\text { San Antonio, TX }\end{array}$} & \multirow{2}{*}{$\begin{array}{l}\text { FAA Office of Aviation Medicine } \\
800 \text { Independence Ave., S.W. } \\
\text { Washington, DC } 20591\end{array}$} & \\
\hline & & 11. Contract or Grant No. \\
\hline \multirow{3}{*}{\multicolumn{2}{|c|}{$\begin{array}{l}\text { 12. Sponsoring Agency name and Address } \\
\text { Office of Aviation Medicine } \\
\text { Federal Aviation Administration } \\
800 \text { Independence Ave, S.W. } \\
\text { Washington, DC } 20591\end{array}$}} & 12. Type of Report and Period Covered \\
\hline & & \\
\hline & & 14. Sponsoring Agency Code \\
\hline
\end{tabular}

15. Supplemental Notes

16. Abstract

An investigation was conducted of the values or worth functions pilots attribute to weather and terrain variables in making decision about flight in a single-engine aircraft under visual flight rules. The research employed a scenariobased judgment task designed to elicit pilot worth functions for visibility, ceiling, precipitation, and terrain features (specifically, flight over flat terrain, mountainous terrain, and over water).

Subjects were asked to consider a proposed cross-country flight of approximately one hour duration over each of the three terrain conditions. They were then given a deck of cards describing various combinations of ceiling, visibility, and precipitation and asked to first rank order the cards in descending order of somfort with flying under the described conditions over the specified terrain and then to assign a numerical rating to each card using a scale of 0 (least comfortable) to 100 (most comfortable). For each subject a linear model was constructed using the comînt ratings as the dependent variable and the visibility, ceiling, and terrain values as the independent variables. A separate linear model was constructed for each subject for each of the three terrain conditions. The regression weights associated with each terrain type were then subjected to hierarchical clustering to identify groups of weight sets differing significantly with respect to worth function emphasis.

Examination of the clusters indicated that pilots could be reliably grouped into four groups for the flat and mountainous terrain scenarios and two groups for the over-water scenario. These clusters are characterized primarily by the average degree of comfort which the subjects expressed in flying under the conditions described, by the nature of their efficiency of utilization of information (multiplicative models compared to simpler singie variable models), and demographic characteristics such as age and aircraft ownership.

17. Kay Words

Pilots, Aircraft, Decision-Making, Aviation Safety, Aircraft Pilots, Policy-Capturing, Mathematical Modeling

19. Security Ctassif. (of this report) Unclassified

Form DOTF $1300.7(8.32)$

\section{Distribution Statement}

Document is available to the public through the National Technical Information Service Springfield, Virginia 22161

20. Security Classif. lof this page)
Unclassified

\begin{tabular}{|c|l|}
\hline $\begin{array}{c}\text { 21. No. of Pages } \\
56\end{array}$ & 22. Price \\
\hline
\end{tabular}




\title{
ACKNOWLEDGMENTS
}

Collection of data from civilian pilots on which this research report is based was made possible by the cooperation of numerous individuals. We acknowledge their very important contribution. Especiaily, we express appreciation to:

\author{
Owen Russel \\ San Antonio, Texas \\ Federal Aviation Administration Office.
}

Mr. Russel not only was responsible for locating and arranging for collection of data from the civilian pilots, but he participated as a proctor during group administration. His assistance made possible the generation of the research report.

Others contributed significantly to the development of data collection instruments and to data collection. We also express our sincere appreciation to the following persons and organizations with which they are affiliated:
Marvin G. Ledyard
Alcides Dreumont
William Cervinske
Bruce D. Hoover
Gary J. Northam
L.W. Fournier
Huey McDonald
Lauren Fast
Jim Wright
Randy Smedly
Virginia McDaniel
Thomas E. Taylor

Finally, we are appreciative of the time and interest of the 152 anonymous pilots who provided the raw data employed in the analysis. 


\title{
ACKNOWLEDGMENTS
}

Collection of data from civilian pilots on which this research report is based was made possible by the cooperation of numerous individuals. We acknowledge their very important contribution. Especially, we express appreciation to:

\author{
Owen Russel \\ San Antonic, Texas \\ Federal Aviation Administration Office.
}

Mr. Russel not only was responsible for locating and arranging for collection of data from the civilian pilots, but he participated as a proctor during group administration. His assistance made possible the generation of the research report.

Others contributed significantly to the development of data collection instruments and to data collection. We also express our sincere appreciation to the following persons and organizations with which they are affiliated:
Marvin G. Ledyard
Alcides Dreumont
William Cervinske
Bruce D. Hoover
Gary J. Northam
L.W. Fournier
Huey McDonald
Lauren Fast
Jim Wright
Randy Smedly
Virginia McDaniel
Thomas E. Taylor

Finally, we are appreciative of the time and interest of the 152 anonymous pilots who provided the raw data employed in the analysis. 


\section{TABLE OF CONTENTS}

INTRODUCTION

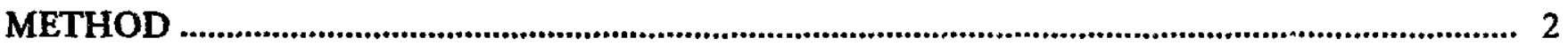

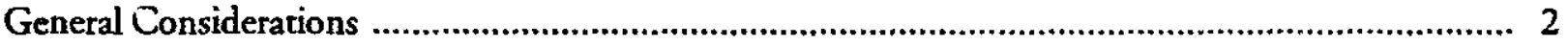

Design Implications of Behavioral Decision Research ............................................................ 3

Data Collection Instrument Development ....................................................................... 4

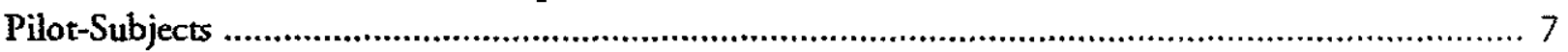

Data Collection Procedure .................................................................................................... 7

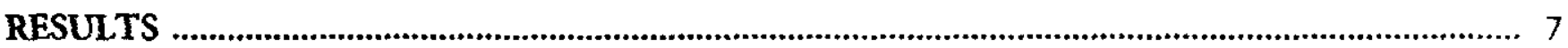

Identification of Worth Funetions ................................................................................. 8

Noncompensatory Strategy Detection ................................................................................ 13

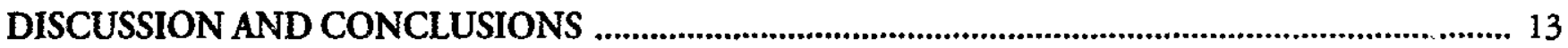

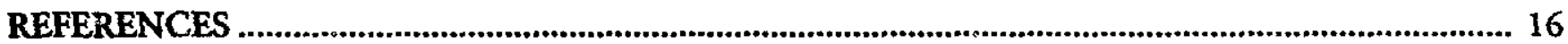

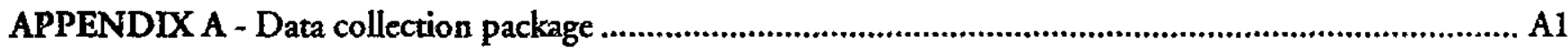

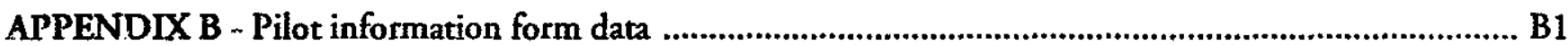

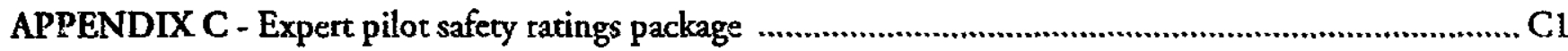

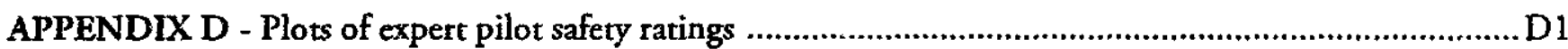

APPENDIX E - Selected pair comparisons among policy groups for each scenario ............................... E1

APPENDIX F - Comprehensive occupational data analysis program ................................................... FI

\section{LIST OF TABLES}

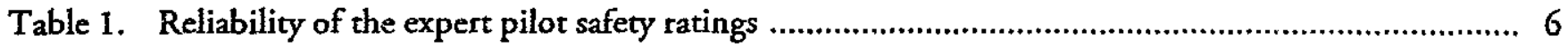

Table 2. Standardized high, medium and low levels of safety variables ..................................................6

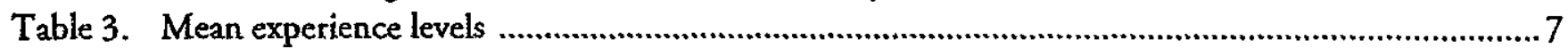

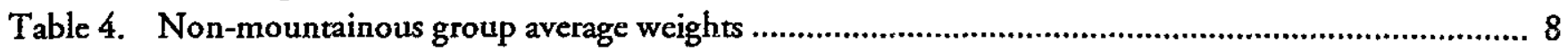

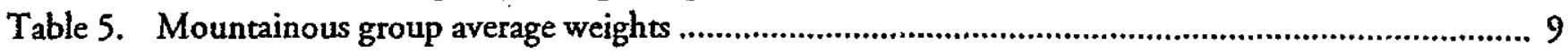

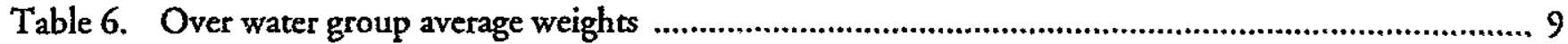

Table 7. Mean demographic variables and comfort levels for non-mountainous scenario groups .............. 10

Table 8. Mean demographic variables and comfort levels for mountairous scenario groups ......................11

Table 9. Mean demographic variables and comfort levels for over-water scenario groups .......................... 12

Table 10. Comparison of compensatory and non-compensatory models .................................................... 14 


\section{EXECUTIVE SUMMARY}

The body of this report details how 152 general aviation pilots were assessed to determine the weights (worth functions) they assigned to the variables of terrain, ceiling, visibility and precipitation. The obtained, analysis results were sufficiently clear to allow the identification (at least tentatively) of discinctly different worth functions. Specifically, four different worth functions were identified and characterized for non-mountainous and mountainous terrain types. Two different worth functions were identified and characterized for over-water terrain. Use of weather information was consistent with expert assessment of the safety risk associated with VFR flight under varying ceiling, visibility, and precipitation conditions over non-mountainous, mountainous, and water terrain. However, while use is consistent, pilots vary in their expressed degree of comfort in flying over the different terrain und $r$ different weather corditions. These differences in comfort level may occur, in part at least, because of:

- Differences of understanding of the risks associated with flying under differing above-minimum levels of visibility, ceiling, and precipitation and how terrain type impacts use of such information.

- Differences in their self-assessment and perception of their ability and/or skill in flying under the varying conditions.

In summary, this study found:

-It is possible to capture reliably pilots' "comfort" policies in terms of emphasis upon terrain, ceiling, visibility, and precipitation using a linear modeling approach.

- Pilots use compensatory judgment rules with sophisticated interactions.

- Pilots generally agree on how to prioritize the safety implications of terrain/weather conditions.
- Pilots' policies tend to fall cleaniy into stable policy groups although the individual pilots who hold those views switch groups according to terrain.

- Pilots' policies vary based upon:

1. General comfort level

2. A mixture of age and general experience

3. Number of hours flown in last 90 days

4. Reasons for flying (employed as pilot versus pleastire flying)

\section{IMPLICATIONS}

- Pilots' use of weather information is consistent with expert assessment of the safety risk associated with VFR flight under varying ceiling, visibility, and precipitation conditions over non-mountainous, mountainous, and water terrain.

-While use is consistent, pilots vary in their expressed degree of comfort in flying over the different terrain under different weather conditions.

- Training or other interventions addressing risk assessment and self-perception would appear to be appropriate. Present use of the Five Hazardous Thought Patterns is one method of addressing self perception. Training directed at improving pilot understanding of the effects of terrain-type on interaction of meteorological conditions is another potential source. Increased emphasis on risk assessment and self perception training and exercises in initial training and in subsequent seminars (FAA-sponsored and otherwise) would seem to be warranted.

- Although the compensatory decison model is used by expert and by many other pilots as well, its use in all situations may not be advisable. Some care and consideration must be observed in training inexperienced pilots to use the decison models of expert pilots, as their injudicious use may be a threat to aviation safety. 


\section{The Use of Weather Information in Aeronautical Decision-Making}

\section{INTRODUCTION}

A National Transportation Safety Board report (NTSB, 1989) reviewed 361 general aviation accidents that occurred between 1983 and 1987 in which Visual Flight Rules (VFR) into instrument meteorological conditions (IMC) was listed as a probable cause or a related factor. (Most accidents have multiple causes/factors assigned as probable.)

Ninety-seven percent of the probable causes were attributed to the flight crew, and $42 \%$ of these cited the manner in which weather information was obtained (or not obtained), assimilated, and used. There were $\mathbf{2 7 6}$ fatal accidents, resulting in 583 fatalities.

An earlier review of aircraft accident data (Jensen, 1982) reported similar data and zoncluded that 80 to $85 \%$ of aircraft accidents can be assigned broadly to pilot error. The review also indicated that $51.6 \%$ of the fatal and $35.1 \%$ of the non-fatal accidents resulted from faulty decision-making. Because of the prominence of pilot error and flight from VFR into IMC as causes of general aviation accidents, the Federal Aviation Administration (FAA) sponsors training interventions on pilot decision-making which address both factors. The interventions focus on both cognitive and affective (or motivational) components of pilot decision-making (Brecke, 1981; Jensen, 1982; Jensen, Adrion, \& Lawton, 1987). These two components differentiate among processes pilots employ in using and evaluating information available to them and making choices about actions to take. The cognitive component deals with the processes by which pilots establish and evaluate the alternatives in a decisionmaking situation. Jensen (1982) proposed that this component relates to pilot ability to search for and establish the relevance of all availabic information regarding a situation, to specify alternative courses of actions, and to determine expected outcomes from each alternative. This component invokes the intellectual, discriminative abilities which depend upon human capabilities to sense, store, retrieve, and integrate information.
From a cognitive perspective, according to Jensen (1982), pilots should discriminate among situational dimensions. He asserts that for discriminative judgment, these important questions must be addressed: 1) Do pilots consider all situational dimensions and do they assign proper weights to the data elements for each of these dimensions? 2) Do pilots efficiently integrate the relevant information from the data elements?

Cognitive training provides information designed to increase pilot awareness of flight safery under adverse conditions and to assist pilots in assigning and integrating proper weights to the data elements. Training consists of exercises demonstrating the risks associated with flying activities and the underlying behavioral causes of typical accidents. The effects of stress on decision-making and the management of stress are also important training elements. Informational materials include data about such factors as causes of accidents by phase of operation and pilot experience, the aeronautical decision-making processes, and weather forecast accuracy and use? Information about weights pilot attribute to flight data elements, however, is not available for use in training or other interventions.

According to Jensen et al. (1987), use of aeronautical decision-making interventions for instrument pilots produces substantial reductions in pilot error rates. Reduction in decisional mistakes attributed to the training ranges from 10 to $50 \%$. Similar training exists for student, private, commercial, and multicrew aircraft pilots.

A very limited amount of research on the cognitive processes of pilot decision-making has been reported. This research, however, has two important findings. First, the feasibility of investigating the in tellectual processes in decision-making through assessment of pilot worth or values pilots attribute to flight data elements has been demonstrated. Second, pilots appear to weight flight data elements differentially, 
because of such factors as experience and training. Flathers, Giffin, \& Rockwell (1982) presented pilots with a diversion-decision scenario requiring an inflight decision to change destinations during a crosscountry flight, because of equipment malfunction. Subjects were presented alternative landing sites varying according to weather conditions, air traffic control facilities. approach, and flight time to reach the sites. Two levels of each variable were represented. Subjects rank-ordered the sites according to their preference of diversion landing site. Conjoint analysis was employed to derive worth functions for each of the four variables. Comparisons of the worth functions among pilots with differing experience and training (e.g., flight hours, source of certification) revealed that pilots differentially weighted the variables. Interactions among the four variables were not found. Flathers et al. also referenced a study by Curry (1976) that reported similar results from a study of approach-to-landing decision making. These results suggest that pilot error in decision making, one of the two most frequently cited probable causes of general aviation accidents, may, in part, occur because pilots do rot assign proper weights to the flight data elements that are available to them.

The present study sought to extend this area of research through an investigation of the values or worth functions pilots attribute to weather and terrain variables in making decisions. The specific objectives were as follows:

- Identify individual weights or worth functions pilots attribute to ceiling, visibility, precipitation, and terrain flight data elements in three representative cross-country flights in a small aircraft.

- Assess interaction effects on assignment of weights that may affect the worth functions of the data elements.

- Assess whether pilots differentially weight these data elements, because of such personal factors as age, flying hours, and source of certification.

\section{METHOD}

\section{General Considerations}

The research reported here employed a scenariobased judgment task designed to elicit pilor worth functions for visibility, ceiling, precipitation, and terrain variables. Behavioral decision research shows that task design is crucial for making consistent judgments. Depending upon the characteristics of a judgment rask, individuals sometimes use a compensatory strategy and other times employ noncompensatory strategies in making decisions. A compensatory strategy is one which processes all relevant information and trades off the good and bad aspects of each alternative. Noncompensatory strategies avoid tradeoffs among values by reducing information processing demands by ignoring potentially relevant problem information, such as selecting a single attribute and sorting on that alone.

A major concern was to design a task that would avoid use of noncompensatory cognitive strategies by the subjects when they were making their judgments. Subjects who employ cognitive decision strategies that are artifacts of the problem task, such as restructuring, application of simple heuristics (representativeness, availability, anchoring) and other more complex noncompensatory processes (e.g., elimination-by aspects, lexicographic) usualiy are trying to reduce cognitive effort. As a result, subjects frequently neglect information relevant to the decision problem (Payne, Bettman, \& Johnson, 1988; Payne, Bettman, \& Johnson, 1992).

The task was intended to facilitate consisterit, compensatory decision strategy utilization by the respondents to make, using Jensen's (1982) terminology, rational judgments. Rational judgment implies that pilots should use weighted-additive strategy processes. In the weighted-additive process pilots should be expected to consider the values of each element or attribute; weight the values of each element by its importance for a safe flight; and sum the weighred values as a basis for overall evaluation of each flight scenario. In practice, however, some pilots may be expected to have developed mixed cognitive strategies (from their experience or training) for considering 
data elements. While some may have weightedadditive strategies which they consistently apply to judgments, other pilots may have developed rules which they apply to some of their judgments that give the appearance of some non-compensatory strategy or heuristic, such as elimination-by-aspects. For example, some pilots may have developed a simple heuristic that they will not make any flight over water regardless of weather conditions; however, weather conditions may have important values when flying over ocher kind of terrain. The possibility of multiple strategies was addressed in the analytic methodology (Appendix F) employed by providing for distinguishing between "real" multiple policies and those that may have been artifacts of the task itself.

\section{Design Implications of Behavioral Decision Research}

Design of the decision task was based on the results of behavioral decision research which indicates that differences in decision strategies within a problem task occur, according to Payne (1982), because "...information processing in decision making, as in other areas of cognition, is highly contingent upon the demands of the task" (p. 382). Different decision strategies can be thought of as different rules for conducting the search among the attributes and alternatives (Payne, Bettman, \& Johnson, 1988). To reduce the likelihood of subjects in this study using strategy variations which are induced by the nature of task itself (versus using their own decision sets), careful atterition was given to response mode and task and context characteristics (Einhorn \& Hogarth 1981; Payne, Bettman, \& Johnson, 1988; Payne, Bettman, \& Johnson, 1992).

Judgment versus Choice Response Mode. Judgment and choice tasks require different cognitive processes. In a judgment task, subjects are provided successive presentations of alternatives to each of which a subject assigns a value reflecting its psychological worth. Sometimes the values are in terms of a rating scale; sometimes the psychological worth might be expressed in terms of the amount of money the subject would pay for the alternative. In a choice task, subjects are presented with two or more alternatives and asked to select the alternative most preferred or the order in which the alternatives are preferred.

Some of the clearest examples of decision reversals have been noted between judgment and choice tasks. Subjects reversed their decision in tasks containing identical information as a function of whether they were required to make judgments among the dimensions or make choices among the dimensions (Payne, 1982). Because of these findings, a judgment task was used in this research. In judgment tasks, subjects seem to select an attribute of an alternative as an anchor and then adjust that anchor based on information associated with other attributes. Such processing is more holistic. The choice mode seems to involve primarily dimensional processing by which dimensions of one alternative are compared with parallel dimensions of other alternatives.

Task and Context Task Factors. Task and context factors cause different aspects of the problem to be salient and evoke different processes for combining information (Payne, Battman, \& Johnson, 1992, p. 90; Payne, 1982; Einhorn \& Hogarth, 1981). Task factors are general characteristics of a decision problem which do not depend upon the particular values of the attributes or alternatives, such as the number of alternatives, number of attributes, information display, and time limits. Context factors, such as similarity of alternatives, are associated with the particular values of the alternatives. The following task factors guided development of the experimental task:

- In general, cognitive effort in responding to a decision task seems to increase as the number of alternatives presented for each choice problem increases. Subjects tend to employ compensatory types of decision strategy when choices are made between only two alternatives. As alternatives are added, subjects tend to use choice strategies, such as the elimination-by-aspects rule. In the task employed in this research, judgments among the weather-terrain scenarios was not required. Subjects considered each weather-terrain scenario independently a: 1 judged their comfort level about flight under the conditions described. 
- In general, increases in the number of attributes or dimensions (e.g., the amount of information) of alternatives increases the variability of strategy and decreases quality of judgments. Subjects are likely to use some decision rule (e.g., elimination by aspects) when faced with complex choices. The design of the problem task in this research limited each scenario to four attributes or dimensions.

- Time pressure seems to affect task complexity. Measures of information search showed that subjects tend to spend more time observing negative information under time pressure. Although no time limit was imposed, most subjects in the study reported here completed the task in less than 50 minutes (including time for administrative instructions).

- Information display also may affect judgmentchoice behavior. Use of attribute information was reported as increased when this information was displayed in an organized manner and that information acquisition (about attributes) tends to proceed in a way consistent with the display format. Studies have demonstrated that displays designed to encourage alternative-based processing tended to produce more alternative-based information processing. Also, completeness of the information displayed is important. Subjects may tend to discount alternatives when there is missing information about one or more attributes. The judgment task presented dimension information consistently across all scenarios. Each scenario contained the same dimensions. Although values varied, dimensions appeared in the same order and format. Other data elements than those represented in the dimensions which could be important in making judgments about the scenarios (e.g., equipment status, time of day, pilot physical and psychological condition) were held constant across all scenarios for two reasons. First, the appearance of missing information was avoided. Second, variations in these elements would have introduced uncontrolled variables into the design.
- The only context variable that could have implications for the proposed research relatis to the similarity of dimensions or attributes. It seems clear that in choice tasks where choices among alternatives is the task, similarity of attributes among alternatives increases the cognitive effort required to make choices. The effort required to make comparisons among alternatives essential to choice-making is increased, thus inducing some non-compensatory strategy, such as elimination-by-aspects (Payne, 1982). Since judgment of each scenario was made independently, the effects of similarity should have been eliminated or minimized.

\section{Data Collection Instrument Development}

Data collection instruments consisted of a) a test booklet (used to obtain pilot background and experience information), b) a set of laminated colored maps (one for each of three terrain types: water, nonmountainous, and mountainous), and c) three sets of en route weather scenarios (each set corresponding to a terrain type). Appendix $A$ is a set of these data collection instruments.

Test Booklets. Booklets consisted of three separate parts. Part one contained instructions for assigning "comfort" ratings to the weather scenarios. Part two elicited demographic information such as certification source, age, total flying hours, total hours flown in the last 90 days. This demographic information paralleled that cited by the National T ransportation Safety Board (NTSB, 1989) as being related to aircraft accidents the NTSB studied from 1983 to 1987 . Part three of the booklet was designed to obtain the pilot-subject's degree of experience flying over each of the three types of terrain, and their experience flying into various levels of precipitation (light rain, moderate rain, heavy snow), visibility ( $1 \mathrm{NM}, 4 \mathrm{NM}, 8 \mathrm{NM}$ ), and ceiling $(800 \mathrm{ft}, 1800 \mathrm{ft}, 4000 \mathrm{ft})$. A 5 -point scale $(0=\mathrm{I}$ have never flown into these or highly similar conditions; $4=I$ have flown into these conditions numerous times $(11+))$ was used for these ratings.

Terrain Maps/Flight Routes. The terrain maps selected were for the Great Lakes (over water), North Texas (nonmountainous) and New Mexico (mountainous) areas 
and were clearly identifiable with respect to these terrain types. In the selection of the over-water terrain map, southern coastal areas were removed from consideration because of limitations imposed on the development of realistic weather scenarios (e.g., snow would not be a condition normally encountered over southern coastal areas). It was felt that local knowledge of terrain, if possessed by some subjects and not others, would act as an uncontrolled independent variable. The importance of minimizing this local knowledge was emphasized by the Shanteau and Nagy (1979) research which indicated that subjects' previous knowledge about a task to be performed influenced their choices in task performance. Since pilots were to be drawn from the San Antonio, Texas area, the route map selected (Great Lakes, North Texas, and New Mexico) minimized the potential impact of local knowledge.

Routes to be flown (City County to Delta County, Michigan for over water, Hereford to Dalhart, Texas for non-mountainous, and Las Vegas to San Juan Pueblo, New Mexico for mountainous) were laid out to minimize impact of restricted, special-use airspace, and low-level military training routes. These flight routes were clearly marked on the corresponding color terrain map. In addition to flight routes, maps were also annotated with local and destination weather and a description of the type and condition of the aircraft being flown (e.g., Cessna 172 without transponder and navigation radio out).

Scenario Development. En route weather scenario content was developed from the NTSB (1989) study of weather-related general aviation accidents from 1983 to 1987 . In addition to a probable cause of VFR flight into IMC conditions, which was the criterion used by the NTSB to select accidents for analysis, $89 \%$ of these accidents were attributed to the following four factors:

$\begin{array}{ll}\text { Terrain conditions } & 225(18.6 \%) \\ \text { Low ceiling } & 216(17.9 \%) \\ \text { Poor visibility } & 448(37.2 \%) \\ \text { Precipitation } & 180(15.3 \%)\end{array}$

As a result of these findings, scenarios were generated (using a multi-stage process) around variations in terrain, ceiling, visibility, and precipitation. Specifically, 81 scenarios were produced to accommodate three levels of each of these four independent attributes. Each scenario was printed on a 5 by 4 inch card, color coded with respect to terrain type, and described a combination of en route weather conditions (ceiling, visibility, and precipitation) encountered during the cruise phase of flight over each of the three terrain types.

The First stage of scenario development focused on the identification and validation of the three levels (low, medium, and high) of ceiling, visibility, and precipitation variables to be used in scenario development. Specifically, an Expert Pilor Safery Ratings Form (Appendix C) was developed and administered to 22 pilot-subjects. This group of pilots had an average of 3,700 hours of total flight time and had an average age of 42 years. Of the 22 pilots, 16 were certified flight instructors and 11 were employed as pilots. These 22 pilots used a 0 -to- 100 point scale $(0=$ Absolutely unsafe $/ 100=$ totally safe) to rate the relative safety of the three routes (over water, normountainous, and mountainous) and of levels of ceiling, visibility, and precipitation with respect to VFR flying by a pilot with 500 hours of flying experience.

These 22 pilot-subjects first provided safety ratings for 8 levels of precipitation (ranging from no precipitation to freezing rain), 12 levels of visibility (ranging from $1 / 2 \mathrm{NM}$ to more than $8 \mathrm{NM}$ ), and 16 levels of ceiling (ranging from 600 feet to over 5000 feet). Interrater agreements for the obtained ratings (standardized to a mean of 5.0 and a standard deviation of 1.0) were compured using the GRPREL function of the Comprehensive Occupational Data Analysis Programs (CODAP; Christal, 1974; Sraley and Weissmuller, 1981). (A brief description of CODAP and its components is provided in Appendix F.) The interrater agreements, shown in Table 1 , were ex:raordinarily high. The interrater agreement $\left(R_{11}\right)$ indicates the degree to which pilots within the policy group agreed on how to sort and rate the 81 weather scenarios with respect to comfort level. Values of 0.20 and above are considered "good agreement" (Staley 
Table 1. Reliability of the Expert Pilot Safety Ratings.

\begin{tabular}{|l|c|c|c|}
\hline Variable Levels & $\begin{array}{c}\mathbf{N} \\
\text { Raters }\end{array}$ & $\mathbf{R}_{\mathbf{1 1}}$ & $\mathbf{R}_{\mathbf{k k}}$ \\
\hline Routes & 22 & .67 & .97 \\
\hline Precipitation Levels & 22 & .88 & .99 \\
\hline Visibility Levels & 22 & .92 & .99 \\
\hline Ceiling Levels & 22 & .92 & .99 \\
\hline All Variable Levels & 22 & .82 & .99 \\
\hline \hline
\end{tabular}

and Weissmuller, 1981). The policy stability measure $\left(R_{k j}\right)$ indicates the expected correlation of this policy with the policy, which would be found in a re-survey of " $k$ " subjects. Over all variables and levels, $R_{11}$ was .82 and $R_{k k}$ was .99 .

To identify values associated with the three levels of precipitation, visibility, and ceiling, means and standard deviations were computed, standardized to a mean of 5.0 and a standard deviation of 1.0 for each of the three attributes, and then plotted. Sets of "High," "Medium," and "Low" values were then identified (by inspection) for each level. The results, shown in Table 2, represented a reasonable spread across the range of values. Appendix D contains the associated plots used.

Three sets of 27 weather scenarios were then generated (one set for each terrain type). Specifically, scenario sets were initially generated such that each scenario within a set was unique with respect to precipitation, visibility, and ceiling level combination (e.g., High/High/High, High/High/Medium, etc.). Within level, however, selection of the specific value was randomized i.e., selection of $5000 \mathrm{ft}, 4000$ $\mathrm{ft}$, or $3500 \mathrm{ft}$ within the high level of the ceiling variable was randomized. Each set of scenarios was then randomly numbered (600-to- 626 for non-mountainous, 700-to-726 for mountainous, and 800-to826 for water).

Prior to finalizing the three sets of scenarios, each set was evaluated with respect to plausibility. Subjectmatter expert judgment was used for this purpose. Specifically, 12 weather experts (meteorologists and
Table 2. Standardized High, Medium and Low Levels of Satety Variables.

\begin{tabular}{|c|c|}
\hline Variable & $\begin{array}{l}\text { Benchmark } \\
\text { value/Level }\end{array}$ \\
\hline \multicolumn{2}{|l|}{ Precipitation } \\
\hline $\begin{array}{l}\text { none } \\
\text { light rain } \\
\text { light snow } \\
\text { moderate rain } \\
\text { moderate snow } \\
\text { heavy rain } \\
\text { heavy snow } \\
\text { freezing rain }\end{array}$ & $\begin{array}{c}\text { 6.745/High } \\
\text { 6.000/High } \\
\text { 5.514/Medium } \\
\text { 5.205/Medium } \\
\text { 4.687/Medium } \\
\text { 4.287/Low } \\
\text { 3.975/Low } \\
\text { 3.589/Low }\end{array}$ \\
\hline \multicolumn{2}{|c|}{ Visibility } \\
\hline $\begin{array}{c}\text { more than } 8 \mathrm{NM} \\
8 \mathrm{NM} \\
7 \mathrm{NM} \\
5 \mathrm{NM} \\
4 \mathrm{NM} \\
3 \mathrm{NM} \\
11 / 2 \mathrm{NM} \\
1 \mathrm{NM} \\
1 / 2 \mathrm{NM}\end{array}$ & $\begin{array}{c}\text { 6.598/High } \\
\text { 6.410/High } \\
\text { 6.165/High } \\
\text { 5.446/Medium } \\
\text { 4.939/Medium } \\
\text { 4.639/Medium } \\
\text { 3.960/Low } \\
\text { 3.896/Low } \\
\text { 3.822/Low }\end{array}$ \\
\hline \multicolumn{2}{|c|}{ Celiling } \\
\hline $\begin{array}{l}5000 \mathrm{ft} \\
4000 \mathrm{ft} \\
3500 \mathrm{ft} \\
2000 \mathrm{ft} \\
1800 \mathrm{ft} \\
1600 \mathrm{ft} \\
900 \mathrm{ft} \\
800 \mathrm{ft} \\
600 \mathrm{ft}\end{array}$ & $\begin{array}{l}\text { 5.419/High } \\
\text { 6.244/High } \\
\text { 6.081/High } \\
\text { 5.393/Medium } \\
\text { 5.010/Medium } \\
\text { 4.702/Medium } \\
\text { 3.928/Low } \\
\text { 3.818/Low } \\
\text { 3.664/Low }\end{array}$ \\
\hline
\end{tabular}

weather observers from the National Weather Service Forecast Office in San Antonio, Texas, and USAF Weather Detachments at Reese AFB, Texas, and Randolph AFB, Texas) were asked to rate the degree to which scenario weanter combinations (precipitation, visibility, and ceiling values) could reasonably be expected to occur together (e.g., heavy snow, $5 \mathrm{NM}$ visibility, and a ceiling of 3500 feet would not be expected to occur simultaneously). Subjects rated each scenario on a 0 -to- 100 scale $(0=$ Totally improbable/100=Very probable). Obtained interrater agreement was high $-R_{11}$ was .63 and $R_{k k}$ was .95 . 
Analysis of the resulting mean ratings led to the replacement of 12 of 81 draft scenarios. Scenarios with mean ratings (standardized to a mean of 5.0 and a standard deyiation of 1.0 ) more than 1.5 standard deviations below the mean rating were considered improbable and replaced. Four scenarios from the non-mountainotis set, three from the mountainous set, and five from the over water set were replaced because of low mean ratings. The replacement scenario within a given set was drawn from one of the other two sets. The scenario with the lowest acceptable mean value (of those scenarios not already used as replacements) was always selected as the replacement scenario. This process ensured that (to the extent possible) an equivalent level weather combination was substituted for the unrealistic weather combination.

\section{Pilot-Subjects}

A total of 152 pilots were tested from January to March 1994. Complete data were not available for two pilots who were subsequently dropped from the study. The remaining pilots (131 males and $19 \mathrm{fe-}$ males) ranged in age from 18 to 79 with a mean age of 42. Total flying hours ranged from 6 to 26,500 with a sample mean of 1,694 hours. Within this sample, 31 were certified flight instructors (CFI/CFII), 57 held private pilot certificates, and 9 were students. The remaining subjects were certified as either commercial or airline transport pilots. Table 3 contains the pilotsubjects self-reported mean experience levels $(0=$ Never flown into condition/4=Flown into condition numerous times).

\section{Data Collection Procedure}

Introductory information was designed to be neutral. No reference was made to research into piloterror and pilot-subjects were allowed to respond anonymously. Subjects were motivated to give their personal judgments and to avoid "book" responses. It was emphasized that the only right answers were the responses a subject chose to make.

Data collection took piace in group settings, with up to 25 pilots in a group. Pilots first read the instructions contained in part one of the test booklet, and then completed parts two (pilot information form) and three (attribute experience ratings). Pilots
Table 3. Mean Experience Levels.

\begin{tabular}{|c|c|c|}
\hline Attribute & Mean & $\begin{array}{c}\text { Standard } \\
\text { Deviation }\end{array}$ \\
\hline Terrain & & \\
Water & 1.0 & .95 \\
Non-mountainous & 3.6 & .95 \\
Mountainous & 1.4 & 1.56 \\
\hline Precipitation & & \\
Light rain & 2.4 & 1.18 \\
Moderate rain & 1.6 & 1.35 \\
Heavy snow & .4 & 1.00 \\
\hline Visibility & & \\
$1 \mathrm{NM}$ & 1.7 & 1.44 \\
$4 \mathrm{NM}$ & 2.7 & 1.29 \\
$8 \mathrm{NM}$ & 3.6 & .84 \\
\hline Ceiling & & \\
$800 \mathrm{ft}$ & 1.7 & 1.55 \\
$1800 \mathrm{ft}$ & 2.9 & 1.23 \\
$4000 \mathrm{ft}$ & 3.6 & .80 \\
\hline
\end{tabular}

were then given the first of three sets of 27 weather scenarios and (using the corresponding terrain map) asked to sort the stack from least comfortable to most comfortable about completing the flight. Next, the pilots were asked to assign a 0-to-100 "comfort" rating $(0=$ least comfortaile about completing the flight $/ 100=$ most comfortable about completing the flight) to each scenario in the set. Pilors wrote their rarirg on each scenario card in a clearly marked box. When pilots completed the ratings for a set of weather scenarios, they were given the next set to complete. The order of presentation of scenario sets to pilotsubjects was randomized.

\section{RESULTS}

Data analysis was designed te address two primary issues. The first focused on the identification and description of weights (worth functions) that pilots attribute to ceiling, visibility, and precipitation with respect to terrain type. This analysis included an assessment of the telationship between pilots' worth functions and associated personal factors such as age, total flying hours, source of certification, etc.. The 
second and more narrow issue involved data analysis designed to detect the extent to which noncompensatory strategies were used by pilot-subjects. Analysis methodology and analysis results associated with the first issue (identification of worth functions) will be described first.

\section{Identification of Worth Functions}

Separate sets of analyses were crinducted for each terrain type. Specifically, each pilot-subject's worth function (i.e., the relative emphasis given to ceiling, visibility, and precipitation with respect to the assigned "comfort" ratings) was computed using the following regression equation:

$$
\mathbf{C F}=\mathbf{A}+\mathbf{B}+\mathbf{C}+\mathbf{A B}+\mathbf{A C}+\mathbf{B C}+\mathbf{A B C}
$$

where $C F$ was a vector of a pilot's 27 weather scenario "comfort" ratings for a given type of terrain; and A, B, and $C$ (and their interactions) were vectors of benchmark values (of the corresponding scenarios) for ceiling, visibility, and precipitation, respectively. A total of 150 sets of regression weights (one set for each pilot-subject) were computed with respect to each terrain type. These individual sets of regression weights were considered to be a pilot-subject's worth function with respect to the given terrain type.

$\mathbf{R}^{2}$ values associated with these weight sets were relatively high. For mountainous terrain, $78 \%$ of the 150 equations had $R^{2}$ values equal to or greater than 70. For the non-mountainous and over water terrain, $60 \%$ of the equations had $\mathrm{R}^{2}$ values equal to or greater than .70 . These $\mathrm{R}^{2}$ values indicate the degree to which pilots' comfort ratings are explained by their worth functions and scenario benchmark values.

The 150 sets of regression weights associated with each terrain type were then subjected to hierarchical clustering (HIER-GRP) to identify groups of weight sets differing significantly with respect to worth function emphasis. Within both mountainous and nonmountainous terrain types, four significantly different policy grcups were detected. Within the over water terrain type, two significantly different policy groups were detected. Tables 4,5 , and 6 display, for the nonmountainous, mountainous, and over water scenarios, respectively, the worth functions for significant policy groups by showing the average standard regression weights which were greater than or equal to .25 . The average $R^{2}$, inter-rater agreement $\left(R_{11}\right)$, policy stability $\left(R_{k k}\right)$, and average comfort level (CF) are also reported for each group and terrain.

Tables 7, 8, and 9 contain the background data for pilots in each subject identified policy group for the non-mountainous, mountainous, and overwater scenarios, respectively. In addition, Appendix $E$ lists the results of a series of pair comparisons of demographic and comfort level values for policy groups in each of the three scenarios. Since the purpose of these pair compaxisons was to assist in developing an understanding of the critical differences among these groups, only those comparisons that were found to be statis. tically significant are listed.

Table 4. Non-mountainous Group Average Weights.

\begin{tabular}{|c|c|c|c|c|}
\hline A (Ceiling) & - & - & - & - \\
\hline B (Visibility) & - & - & - & - \\
\hline C (Precipitation) & - & - & 0.51 & - \\
\hline$A B$ (Ceiling/Nisibililty) & 1.5 & - & 0.34 & - \\
\hline AC (Ceiling/Precipitation) & 0.8 & - & - & 0.25 \\
\hline BC (Visibility/Precipitation) & - & - & - & - \\
\hline ABC (Ceiling/Visibility/Precipitation) & - & 2.1 & - & 0.37 \\
\hline Average $\mathbf{R}^{2}$ & 0.79 & 0.77 & 0.66 & 0.58 \\
\hline Rater Agre ement, $\mathbf{R}$ & 0.57 & 0.53 & 0.40 & 0.35 \\
\hline Policy Stability, $R{ }^{11}$ & 0.98 & 0.98 & 0.95 & 0.95 \\
\hline Average Comfort tevel & 32.0 & 28.0 & 50.0 & 17.0 \\
\hline Number of subjects & 34.0 & 52.0 & 27.0 & 37.0 \\
\hline
\end{tabular}


Table 5. Mcuntainous Group Average Weights.

$\begin{array}{llll}\text { GP1 } & \text { GP2 } & \text { GP3 } & \text { GP4 }\end{array}$
A (Ceiling)
B (Visibility)
C (Precipitation)
$A B$ (Ceiling/Nisibililty)
AC (Ceiling/Precipitation)
BC (Visibility/Precipitation)

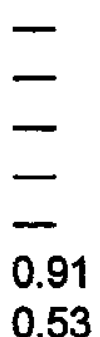
$\overline{ }$
$\overline{=}$
$\bar{z}$
$-$
ABC (Ceiling/Nisibility/Precipitation)
0.53
2.3
0.51
1.1
0.29
Average $\mathrm{R}^{2}$
0.83
0.49
0.80
0.53
$-$
0.99
29.0
36.0
Average Comfort Level
Number of subjects
14.0
69.0
$-$
0.58
0.75
0.44
0.60
0.96
46.0
31.0
0.35
17.0
36.0

Table 6. Over Water Group Average Weights.

$$
\text { GP-A GP-B }
$$
A (Ceiling)
B (Nisibility)
C (Precipitation)

AB (CeilingNisibility)

AC (Ceiling/Precipitation)

BC (Visibility/Precipitation)

ABC (Ceiling/Visibility/Precipitation)

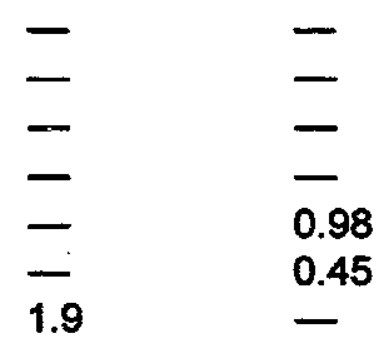

Average $\mathbf{R}^{2}$

0.69

0.67

Rater Agreement, $\mathbf{R}$

Policy Stability, $\mathbf{R}$

0.43

0.35

0.99

0.95

Average Comfort kevel

Number of subjects

27.0

40.0

112.0

38.0 
Table 7. Mean Demographic Variables and Comfort Levels for NonMountainous Scenario Groups.

\begin{tabular}{|c|c|c|c|c|}
\hline \multirow[t]{2}{*}{ Background Variable } & \multicolumn{4}{|c|}{ Non-mountainous Groups } \\
\hline & $\begin{array}{c}\text { GP1 } \\
\text { S-N }\end{array}$ & $\underset{J-N}{\text { GP2 }}$ & $\begin{array}{c}\text { GP3 } \\
\text { J-B }\end{array}$ & $\begin{array}{l}\text { GP4 } \\
\text { S-C }\end{array}$ \\
\hline Number of Subjects & 34 & 52 & 27 & 37 \\
\hline $\begin{array}{l}\text { Flying History } \\
\text { Total Hours } \\
\text { Last } 90 \text { Days }\end{array}$ & $\begin{array}{r}1942 \\
51\end{array}$ & $\begin{array}{r}1516 \\
37\end{array}$ & $\begin{array}{r}1869 \\
47\end{array}$ & $\begin{array}{r}1679 \\
25\end{array}$ \\
\hline Average Age & 44 & 41 & 38 & 46 \\
\hline Percent instrument Rated & $53 \%$ & $38 \%$ & $48 \%$ & $42 \%$ \\
\hline Percent Owning Aircraft & $32 \%$ & $44 \%$ & $19 \%$ & $41 \%$ \\
\hline Percent Female & $12 \%$ & $17 \%$ & $4 \%$ & $14 \%$ \\
\hline Mean Terrain Experience & 3.50 & 3.65 & 3.41 & 3.49 \\
\hline $\begin{array}{l}\text { Mean Precipitation Experience } \\
\text { Light Rain } \\
\text { Moderate Rain } \\
\text { Heavy Snow }\end{array}$ & $\begin{array}{r}2.62 \\
1.79 \\
.38\end{array}$ & $\begin{array}{l}2.50 \\
1.71 \\
.33\end{array}$ & $\begin{array}{r}2.41 \\
1.63 \\
.67\end{array}$ & $\begin{array}{r}2.11 \\
1.27 \\
.38\end{array}$ \\
\hline $\begin{array}{l}\text { Mean Visibility Experience } \\
1 \mathrm{NM} \\
4 \mathrm{NM} \\
8 \mathrm{NM}\end{array}$ & $\begin{array}{l}1.62 \\
2.74 \\
3.38\end{array}$ & $\begin{array}{l}1.79 \\
2.92 \\
3.77\end{array}$ & $\begin{array}{l}1.85 \\
3.00 \\
3.70\end{array}$ & $\begin{array}{l}1.38 \\
2.24 \\
3.30\end{array}$ \\
\hline $\begin{array}{l}\text { Mean Ceiling Experience } \\
800 \mathrm{ft} \\
1800 \mathrm{ft} \\
4000 \mathrm{ft}\end{array}$ & $\begin{array}{l}1.65 \\
2.88 \\
3.56\end{array}$ & $\begin{array}{l}1.75 \\
3.13 \\
3.81\end{array}$ & $\begin{array}{l}1.78 \\
2.93 \\
3.67\end{array}$ & $\begin{array}{l}1.62 \\
2.46 \\
3.38\end{array}$ \\
\hline $\begin{array}{l}\text { Percent Using Weather Source } \\
\text { FAA/FSS } \\
\text { TV/Radio } \\
\text { Other } \\
\text { None }\end{array}$ & $\begin{array}{r}74 \% \\
33 \% \\
0 \% \\
0 \%\end{array}$ & $\begin{array}{c}56 \% \\
32 \% \\
12 \% \\
4 \%\end{array}$ & $\begin{array}{r}56 \% \\
35 \% \\
7 \% \\
3 \%\end{array}$ & $\begin{array}{c}68 \% \\
26 \% \\
13 \% \\
1 \%\end{array}$ \\
\hline Percent Filing Flight Plan* & $58 \%$ & $55 \%$ & $45 \%$ & $57 \%$ \\
\hline $\begin{array}{l}\text { Percent Certificated Held } \\
\text { PP } \\
\text { COMIATP } \\
\text { CFI/CFII }\end{array}$ & $\begin{array}{l}53 \% \\
32 \% \\
210 \%\end{array}$ & $\begin{array}{l}58 \% \\
37 \% \\
21 \%\end{array}$ & $\begin{array}{l}56 \% \\
22 \% \\
26 \%\end{array}$ & $\begin{array}{l}70 \% \\
24 \% \\
16 \%\end{array}$ \\
\hline $\begin{array}{l}\text { Percent Flying } \\
\text { Job-employed as Pilot } \\
\text { Business/Work Related } \\
\text { Pleasure }\end{array}$ & $\begin{array}{l}21 \% \\
11 \% \\
61 \%\end{array}$ & $\begin{array}{l}17 \% \\
7 \% \\
74 \%\end{array}$ & $\begin{array}{l}23 \% \\
11 \% \\
60 \%\end{array}$ & $\begin{array}{l}3 \% \\
6 \% \\
85 \%\end{array}$ \\
\hline Average Comfort Level & 32 & 28 & 50 & 17 \\
\hline Average $\mathbf{R}^{2}$ & .79 & .77 & .66 & .58 \\
\hline
\end{tabular}

* Letter choices were converted to a $0-$ to-100 range: $a=100, b=75, c=50, d=25, e=0$. 
Table 8. Mean Demographic Variables and Comfort Levels for Mountainous Scenario Groups.

\begin{tabular}{|c|c|c|c|c|}
\hline \multirow[t]{2}{*}{ Background Variable } & \multicolumn{4}{|c|}{ Mountainous Groups } \\
\hline & $\begin{array}{l}\text { GP1 } \\
\text { S-N }\end{array}$ & $\begin{array}{c}\text { GP2 } \\
\text { J-N }\end{array}$ & $\underset{\text { J-B }}{\text { GP3 }}$ & $\begin{array}{l}\text { GP4 } \\
\text { S-C }\end{array}$ \\
\hline Number of Subjects & 14 & 69 & 31 & 36 \\
\hline $\begin{array}{l}\text { Flying History } \\
\text { Total Hours } \\
\text { Last } 90 \text { Days }\end{array}$ & $\begin{array}{c}1969 \\
47\end{array}$ & $\begin{array}{c}1963 \\
49\end{array}$ & $\begin{array}{c}561 \\
34\end{array}$ & $\begin{array}{c}2140 \\
21\end{array}$ \\
\hline Average Age & 51 & 41 & 34 & 48 \\
\hline Percent instrument Rated & $51 \%$ & $36 \%$ & $50 \%$ & $39 \%$ \\
\hline Percent Owning Aircraft & $43 \%$ & $39 \%$ & $16 \%$ & $4.4 \%$ \\
\hline Percent Female & $7 \%$ & $10 \%$ & $6 \%$ & $25 \%$ \\
\hline Mean Terrain Experience & 1.57 & 1.58 & 1.10 & 1.36 \\
\hline $\begin{array}{l}\text { Mean Precipitation Experience } \\
\text { Light Rain } \\
\text { Moderate Rain } \\
\text { Heavy Snow }\end{array}$ & $\begin{array}{r}2.50 \\
2.00 \\
.36\end{array}$ & $\begin{array}{r}2.59 \\
1.81 \\
.43\end{array}$ & $\begin{array}{r}2.10 \\
1.19 \\
.19\end{array}$ & $\begin{array}{r}2.31 \\
1.42 \\
.58 \\
\end{array}$ \\
\hline $\begin{array}{l}\text { Mean Visibility Experience } \\
1 \mathrm{NM} \\
4 \mathrm{NM} \\
8 \mathrm{NM}\end{array}$ & $\begin{array}{l}1.86 \\
3.14 \\
3.57\end{array}$ & $\begin{array}{l}1.90 \\
2.94 \\
3.72\end{array}$ & $\begin{array}{l}1.35 \\
2.61 \\
3.55\end{array}$ & $\begin{array}{l}1.39 \\
2.25 \\
3.28\end{array}$ \\
\hline $\begin{array}{l}\text { Mean Ceiling Experience } \\
800 \mathrm{ft} \\
1800 \mathrm{ft} \\
4000 \mathrm{ft}\end{array}$ & $\begin{array}{l}2.43 \\
3.50 \\
3.86\end{array}$ & $\begin{array}{l}1.84 \\
3.10 \\
3.77\end{array}$ & $\begin{array}{l}1.19 \\
2.52 \\
3.58\end{array}$ & $\begin{array}{l}1.58 \\
2.50 \\
3.28\end{array}$ \\
\hline $\begin{array}{l}\text { Percent Using Weather Source } \\
\text { FAAFSS } \\
\text { T//Radio } \\
\text { Other } \\
\text { None }\end{array}$ & $\begin{array}{r}58 \% \\
24 \% \\
7 \% \\
2 \% \\
\end{array}$ & $\begin{array}{r}68 \% \\
32 \% \\
11 \% \\
1 \% \\
\end{array}$ & $\begin{array}{r}69 \% \\
28 \% \\
5 \% \\
3 \% \\
\end{array}$ & $\begin{array}{r}64 \% \\
35 \% \\
17 \% \\
3 \% \\
\end{array}$ \\
\hline Percent Filing Flight Plan ${ }^{*}$ & $44 \%$ & $55 \%$ & $54 \%$ & $56 \%$ \\
\hline $\begin{array}{l}\text { Percent Certificates Held } \\
\text { PP } \\
\text { COM/ATP } \\
\text { CFI/CFII }\end{array}$ & $\begin{array}{l}36 \% \\
36 \% \\
29 \%\end{array}$ & $\begin{array}{l}59 \% \\
33 \% \\
22 \%\end{array}$ & $\begin{array}{l}68 \% \\
16 \% \\
16 \%\end{array}$ & $\begin{array}{l}61 \% \\
33 \% \\
19 \%\end{array}$ \\
\hline $\begin{array}{l}\text { Percent Flying } \\
\text { Job-employed as Pilot } \\
\text { Business/Work Related } \\
\text { Pleasure }\end{array}$ & $\begin{array}{l}18 \% \\
12 \% \\
66 \%\end{array}$ & $\begin{array}{r}22 \% \\
8 \% \\
62 \%\end{array}$ & $\begin{array}{r}12 \% \\
9 \% \\
76 \%\end{array}$ & $\begin{array}{r}5 \% \\
7 \% \\
86 \%\end{array}$ \\
\hline Average Comfort Level & 36 & 29 & 46 & 17 \\
\hline Average $\mathbf{R}^{2}$ & .83 & .80 & .75 & 60 \\
\hline
\end{tabular}

* Letter choices were converted to a 0 -to-100 range: $a=100, b=75, c=50, d=25, e=0$. 
Table 8. Mean Demographic Variables and Comfort Levels for over-Water Scenario Groups.

\begin{tabular}{|c|c|c|}
\hline \multirow[t]{2}{*}{ Background Variable } & \multicolumn{2}{|c|}{ Over-Water Groups } \\
\hline & $\begin{array}{c}\text { GP-A } \\
T-N\end{array}$ & $\underset{T-B}{\text { GP-B }}$ \\
\hline Number of Subjects & 112 & 38 \\
\hline $\begin{array}{l}\text { Flying History } \\
\text { Total Hours } \\
\text { Last } 90 \text { Days }\end{array}$ & $\begin{array}{r}1896 \\
39\end{array}$ & $\begin{array}{r}1187 \\
39\end{array}$ \\
\hline Average Age & 43 & 40 \\
\hline Percent Instrument Fated & $46 \%$ & $39 \%$ \\
\hline Percent Owning Aircraft & $39 \%$ & $26 \%$ \\
\hline Percent Female & $12 \%$ & $16 \%$ \\
\hline Mean Terrain Experience & 1.04 & .89 \\
\hline $\begin{array}{l}\text { Mean Precipitation Experience } \\
\text { Light Rain } \\
\text { Moderate Rain } \\
\text { Heavy Snow }\end{array}$ & $\begin{array}{r}2.49 \\
1.71 \\
.43\end{array}$ & $\begin{array}{r}2.18 \\
1.29 \\
.37\end{array}$ \\
\hline $\begin{array}{c}\text { Mean Visibility Experience } \\
1 \mathrm{NM} \\
4 \mathrm{NM} \\
8 \mathrm{NM}\end{array}$ & $\begin{array}{l}1.74 \\
2.80 \\
3.62\end{array}$ & $\begin{array}{l}1.42 \\
2.50 \\
3.37\end{array}$ \\
\hline $\begin{array}{l}\text { Mean Ceiling Experience } \\
800 \mathrm{ft} \\
1800 \mathrm{ft} \\
4000 \mathrm{ft}\end{array}$ & $\begin{array}{l}1.77 \\
2.80 \\
3.65\end{array}$ & $\begin{array}{l}1.50 \\
2.68 \\
3.53\end{array}$ \\
\hline $\begin{array}{l}\text { Percent Using Weather Source } \\
\text { FAAFSS } \\
\text { TVIRadio } \\
\text { Other } \\
\text { None }\end{array}$ & $\begin{array}{r}67 \% \\
33 \% \\
12 \% \\
1 \%\end{array}$ & $\begin{array}{r}65 \% \\
24 \% \\
7 \% \\
5 \%\end{array}$ \\
\hline Percent Filing Flight Plan* & $56 \%$ & $50 \%$ \\
\hline $\begin{array}{l}\text { Percent Certificates Held } \\
\text { PP } \\
\text { COMATP } \\
\text { CFI/CFII }\end{array}$ & $\begin{array}{l}58 \% \\
33 \% \\
21 \%\end{array}$ & $\begin{array}{l}63 \% \\
21 \% \\
18 \%\end{array}$ \\
\hline $\begin{array}{l}\text { Percent Flying } \\
\text { Job-employed as Pilot } \\
\text { Business/Work Related } \\
\text { Pleasure }\end{array}$ & $\begin{array}{r}14 \% \\
9 \% \\
72 \%\end{array}$ & $\begin{array}{r}19 \% \\
6 \% \\
67 \%\end{array}$ \\
\hline Average Comfort Level & 27 & 40 \\
\hline Average $R^{2}$ & .69 & .67 \\
\hline
\end{tabular}

* Letter choices were converted to a 0 -to-100 range: $a=100, b=75, c=50, d=25, e=0$. 
With respect to non-mountainous terrain (Table 4), four worth functions could be interpreted. The most obvious of these were those associated with GP1 and GP2, which we have chosen to designate as the Senior-Nominal Group and Junior-Nominal Group, respectively, based upon an inspection of the significant differences among demographic characteristics and comfort levels of the groups, as shown in Table 7 and Appendix $E$. The worth function associated with GP1 seemed to be related to pilots who emphasized the interactive relationship of ceiling and visibility in their assessment of flight completion comfort. The function associated with GP2 appeared to represent pilots who interactively related ceiling, visibility, and precipitation. The remaining functions for GP3 (Junior-Bold) and GP4 (Senior-Cautious) were less distinct (i.e., did not have standard weights greater or equal to 1.0). All mountainous terrain worth functions (Table 5) appeared to involve the interrelationship of pairs of weather attributes or all three weather attributes. With respect to over-water terrain (Table 6), there were two relatively distinct functions. The function for GP-A (Total-Nominal) was similar to the previously cited GP2 (Junior-Nominal) functions. Significant differences in background variable values among non-mountainous, mountainous, and overwater groups are listed in Appendix E.

\section{Noncompensatory Strategy Detection}

To determine the extent to which noncompensatory strategies were used by the subject-pilots in assigning weather scenario comfort ratings, the relationships (correlations) between comfort ratings and sets of compensatory and noncompensatory models were examined and compared. Specifically, the standardized scenario benchmark ratings (which had been standardized to a mean of 5.0 and a standard deviation of 1.0 for all scenarios) were first transformed (using sets of transformations designed to simulate compensatory and noncompensatory policies), and then correlated with pilot-subjects' scenario mean comfort ratings for each terrain type. The compensatory model set consisted of additive, multiplicative, and worst-factor cut-off models. The noncompensatory set consisted of sets of single-factor, continuous, and cutoff models (one set for each factor - ceiling, visibility, and precipitation).
Within the compensatory model set, the additive model summed the three benchmark factors, and implied equal weights for the three factors. The multiplicative models (both two and three factor models) cross-multiplied benchmark values, implied a policy in which one or more factors may introduce a dampening effect which can overpower the level of the other factors. The worst-factor cut-off models used the lowest of the three benchmark values, and implied a policy in which the poorest of the three factors became the only focus. Within the noncompensatory set, models representing policies associated with continuous single factors and single-factor cutoffs (ceiling, visibility, or precipitation) were used.

Table 10 lists the compensatory and noncompensatory models used, and their respective correlations with pilot-subject mean comfort ratings. It may be seen that in almost all instances, the highest correlations (across terrain types) were always associated with the compensatory models. Of these compensatory models, the three-factor additive and multiplicative models consistently showed the strongest relationships with assigned comfort ratings. Overall results tend to support the contention that compensatory strategies were widely used by pilot subjects.

\section{DISCUSSION AND CONCLUSIONS}

First, let us note that the results of this study must be considered tentative in that the worth functions were derived from a subject-pilot sample primarily experienced in flying over non-mountainous terrain. Because of the terrains used and the experience base of the pilots sampled, this study may produce unstable weights for the "water" and "mountain" terrains as experience levels were very low. In particular, low experience levels over water may account for the fact that only two policies were detected. Additional studies in other parts of the country using subjects with higher levels of mountainous and over-water flying experience) will be required to assess the stability of the obtained worth functions. These studies will also allow us to evaluate the degree to which the compensatory and noacompensatory models are used by pilot in these settings. 
Table 10. Comparison of Compensatory and NonCompensatory Models.

\begin{tabular}{|c|c|c|c|}
\hline \multirow[t]{2}{*}{ Afodels Used } & \multicolumn{3}{|c|}{ Obtained Correlation (r) } \\
\hline & Nori-mountainous & Mountainous & Water \\
\hline $\begin{array}{l}\text { Compensatory Models } \\
A+B+C \text { (Additive) } \\
A * B * C \text { (Multiplicative) } \\
A * B \text { (Multiplicative) } \\
A * C \text { (Multiplicative) } \\
B * C \text { (Multiplicative) }\end{array}$ & $\begin{array}{l}.94 \\
.96 \\
.86 \\
.76 \\
.79\end{array}$ & $\begin{array}{l}.93 \\
.96 \\
.84 \\
.82 \\
.86\end{array}$ & $\begin{array}{l}.83 \\
.89 \\
.65 \\
.79 \\
.73\end{array}$ \\
\hline 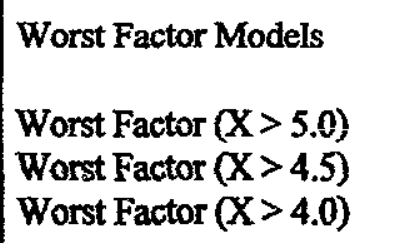 & $\begin{array}{l}.69 \\
.80 \\
.76\end{array}$ & $\begin{array}{l}.71 \\
.82 \\
.79\end{array}$ & $\begin{array}{l}.54 \\
.78 \\
.74\end{array}$ \\
\hline $\begin{array}{l}\text { Noncompensatory Models } \\
\text { A } \\
A(X>5.0) \\
A(X>4.5) \\
A(X>4.0) \\
\text { B } \\
\text { B }(X>5.0) \\
B(X>4.5) \\
B(X>4.0) \\
C \\
C(X>5.0) \\
C(X>4.5) \\
C(X>4.0)\end{array}$ & $\begin{array}{l}.48 \\
.44 \\
.38 \\
.38 \\
.67 \\
.56 \\
.62 \\
.62 \\
.60 \\
.60 \\
.53 \\
.35\end{array}$ & $\begin{array}{l}.53 \\
.55 \\
.42 \\
.42 \\
.62 \\
.53 \\
.46 \\
.46 \\
.73 \\
.67 \\
.56 \\
.55\end{array}$ & $\begin{array}{l}.46 \\
.46 \\
.35 \\
.35 \\
.48 \\
.41 \\
.46 \\
.46 \\
.62 \\
.57 \\
.50 \\
.41\end{array}$ \\
\hline
\end{tabular}


Subject to that caveat, the obtained analysis results were sufficiently clear to allow the identification (at least tentatively) of distinctly different worth functions. Specifically, four different worth functions were identified and characterized for non-mountainous and mountainous terrain rypes. Two different worth functions were identified and characterized for over-water terrain. Pilot use of weather information was consistent with expert assessment of the safety risk associated with VFR flight under varying ceiling, visibility, and precipitation conditions over nonmountainous, mountainous, and water terrain. However, while use is consistent, pilots vary in their expressed degree of comfort in flying over the different terrain under different weather conditions. These differences in comfort level may occur, in part at least, because of:

- Differences of understanding of the risks associated with flying under differing above-minimum levels of visibility, ceiling, and precipitation and how terrain type impacts use of such information.

- Differences in their self-assessment and perception of their ability and/or skill in flying under the varying conditions.

Training of other interventions addressing risk assessment and self-perception would appear to be appropriate. The use of training directed at the Five Hazardous Thought Patterns is one method of addressing self perception. Training directed at improving pilot understanding of the effects of terrain-type on interaction of meteorological conditions is another potential source. Increased emphasis on risk assessment and self perception training and exercises in initial training and in subsequent seminars (FAAsponsored and otherwise) would seem to be warranted. Careful consideration must begiven, however, to the desired outcome of this training. The present study has shown that many pilots use a compensatory model for evaluating weather information, however no data have been collected to denonstrate that the use of a compensatory model is appropriate for all or even the majority of pilots.

Consider the implications of a cornpensatory model in which a high value for one variable (say, visibility)

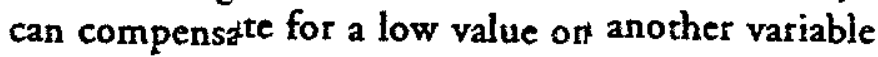

(say, ceiling) in making the determination of the statability of the weather conditions for flight. From the standpoint of information processing, this may be an efficient use of information, however it may also lead pilots to make poor decisions under some circumstances. It may be argued that in many situations (for example, in mountain flying) a noncompensatory model should be used. One such model might set a minimum value for ceiling values (sufficient to clear all mountain peaks, for example) which must be met. regardless of the visibility. That is, in such a model, having a very high visibility does not compensare for ha. $\mathrm{g}$ a low ceiling. Under those circumstances, training inexperienced pilots to use the compensatory model used by experts might be inappropriate and could, in fact, lead to a decrease in safety. Indeed, the dominance of the compensatory models held by centralTexas pilots might partially account for accidents involving these pilots when they fly into mountainous areas.

Thus, the use of a compensatory model, even though it is the favored mode, may be hazardous under some circumstances. Training might therefore be developed that would allow pilots to assess their personal decision making model, and which would train them in the use of non-compensatory models where such models might reduce risk.

In summary, this srudy found:

-It is possible to capture reliably pilots' "comfort" policies in terms of emphasis upon terrain, ceiling, visibility, and precipitation using a linear modeling approach.

- Pilots use compensatory judgment rules with sophisticated interactions.

- Pilots generally agree on how to prioritize the safety implications of terrain/weather conditions. - Pilots policies tead to fall cleanly into stable policy groups although the individual pilots who hold those views switch groups according to terrain.

- Pilots' policies vary based upon:

1. General comfort level

2. A mixture of age and general experience

3. Number of hours flown in last 90 days

4. Reasons for flying (employed as pilot versus pleasure flying) 


\section{REFERENCES}

Brecke, P. (1981). Instructional design for aircrew judgment training. Proceedings of the First Aviation Psychology Symposium. Columbus, OH: Ohio State University, 145-160.

Christal, R.E. (1974). The United States Air Force occupational research project. (AFHRL-TR-73-75, AD774 574). Lackland AFB, TX: Occupational Research Division, Air Force Human Resources Laboratory

Curry, R. (1976). Worth assessment of approach to landing. Proceedings of the annual conference on manual control. NASA teport TX-73. University of Illinois, Urbana, IL: 585-591.

Einhorn, H.J. \& Hogarth, R.J. (1981). Behavioral decision theory: processes of judgment and choice. In Rosenzweig, M.R. \& Porter, L.W. (Eds), Annual review of psychology, Palo Alto, CA: 32, 53-88.

Flathers, G.W., Giffin, W.C., \& Rockwell, T. (1982) A study of decision-making behavior of aircraft $\mathrm{pi-}$ lots deviating from a planned flight. Aviation, space and environmental medicine, 53, 958-963.

Jensen, R.S (1982). Pilor judgment: Training and evaluation. Human factors, 24, 61-73.

Jensen, R.S., Adrion, J., \& Lawton, R. S. (1987), Aeronautical decision making for instrumentpilots. DOT/ FAA/PM-86/43. U.S. Department of Transportation, Federal Aviation Administration, Washington, D.C.
National Transportation Safety Board Safery Report, (1989). General aviation accidents involving visual flight rules flight into instrument meteorological conditions. NTSB/SR-89/01, National Transportation Safety Board, Bureau of Safety Programs: Washingcon, D. C.

Payne, J.W. (1982). Contingent decision behavior. Psychological Bulletin, 92, 382-402.

Payne, J.W., Bettman, J.R., \& Johnson, E.J. (1988). Adaptive strategy selection in decision making. Journal of Experimental Pychology, 14, 534-552.

Payne, J.W., Bettman, J.R., \& Johnson, E.J. (1992). Behavioral decision research: $A$ constructive processing perspective. In Rosenzweig, M.R. \& Porter, L.W. (Eds), Annual review of psychology, Palo Alto, CA: 43, 55-86.

Shanteau, J.,\& Nagy, G.F. (1979). Probability of acceptance in dating choice. Journal of Personality and Social Psychology, 37, 522-533.

Staley, M.R., \& Weissmuller, J.J (1981). Interrater Reliability: The development of an automated analysis tool. (AFHRL-TP-81-42). Brooks AFB, TX: Technical Services Division, Air Force Human Resources Laboratory 
APPENDIX A

DATA COLLECTION PACKAGE 
Rate your comfort level about proceding given the following weather update $(100=$ The MOST comfortable; $0=$ the LEAST comfortable):

ENROUTE: A weak cold front has stalled along a line from Sturgeon Bay to Manistique. Ceilings are reported at $5000 \mathrm{ft}$ with visibility of $11 / 2 \mathrm{NM}$ and light rain.

ROUTE 1

Card Number 801

Rate your comfort level about proceding given the following weather update $(100=$ The MOST comfortable; $0=$ the LEAST comfortable $)$ :

ENROUTE: A weak cold front has stalled along a line running west from Amarillo into New Mexico.. Ceilings are reported at $4000 \mathrm{ft}$ with visibility of 1 NM and light rain.

ROUTE 2

Card Number 601

Rate your comfort level about proceding given the following weather update $(100=$ The MOST comfortable; $0=$ the LEAST comfortable):

ENROUTE: A weak cold front has stalled along a running from Santa Fe northeast into Colorado. Ceilings are reported at $600 \mathrm{ft}$ with visibility of 5 NM and freezing rain.

ROUTE 3

Card Number 701 
Weather Combinations: Route 1-Delta County to City County.

\begin{tabular}{|c|c|c|c|}
\hline Scenario & Ceiling & Visibility & Precipitation \\
\hline 800 & 4000 & 7 & moderate rain \\
\hline 801 & 5000 & 1.5 & light rain \\
\hline 802 & 4000 & 4 & none \\
\hline 803 & 5000 & $8+$ & none \\
\hline 804 & 2000 & 3 & none \\
\hline 805 & 1800 & 3 & heavy rain \\
\hline 806 & 1800 & 7 & light snow \\
\hline 807 & 3500 & 1 & heavy rain \\
\hline 808 & 900 & 1.5 & moderate rain \\
\hline 809 & 1800 & 7 & moderate rain \\
\hline 810 & 800 & 1.5 & none \\
\hline 811 & 1600 & 8 & none \\
\hline 812 & 1600 & 3 & heavy snow \\
\hline 813 & 4000 & 5 & light snow \\
\hline 814 & 900 & 0.5 & heavy snow \\
\hline 815 & 1600 & 1.5 & heavy rain \\
\hline 816 & 5000 & 0.5 & moderate rain \\
\hline 817 & 600 & 8 & moderate rain \\
\hline 818 & 600 & 7 & none \\
\hline 819 & 1600 & 1.5 & moderate snow \\
\hline 820 & 5000 & $8+$ & freezing rain \\
\hline 821 & 900 & 5 & none \\
\hline 822 & 800 & 4 & moderate rain \\
\hline 823 & 1600 & 4 & moderate snow \\
\hline 824 & 1800 & 5 & moderate rain \\
\hline 825 & 1800 & 0.5 & none \\
\hline 826 & 900 & 4 & heavy rain \\
\hline
\end{tabular}


Weather Combinations: Route 2-Dalhart Airport to Hereford Airport.

\begin{tabular}{|c|c|c|c|}
\hline Scenario & Ceiling & Visibility & Precipitation \\
\hline 600 & 5000 & 8 & light snow \\
\hline 601 & 4000 & 1 & light rain \\
\hline 602 & 1600 & 3 & heavy snow \\
\hline 603 & 4000 & 3 & light rain \\
\hline 604 & 2000 & 7 & light snow \\
\hline 605 & 4000 & $8+$ & light rain \\
\hline 606 & 3500 & 0.5 & heavy rain \\
\hline 607 & 1800 & 0.5 & moderate snow \\
\hline 608 & 600 & 0.5 & light snow \\
\hline 609 & 1800 & 4 & none \\
\hline 610 & 800 & $8+$ & light snow \\
\hline 611 & 800 & 8 & none \\
\hline 612 & 1800 & 5 & moderate rain \\
\hline 613 & 600 & 8 & moderate rain \\
\hline 614 & 900 & 4 & heavy rain \\
\hline 615 & 5000 & 1.5 & moderate rain \\
\hline 616 & 1800 & 7 & moderate rain \\
\hline 617 & 900 & 5 & light snow \\
\hline 618 & 900 & 0.5 & heavy rain \\
\hline 619 & 2000 & 1.5 & none \\
\hline 620 & 1800 & 3 & heavy rain \\
\hline 621 & 2000 & 0.5 & freezing rain \\
\hline 622 & 1600 & 4 & moderate snow \\
\hline 623 & 800 & 3 & none \\
\hline 624 & 900 & 1.5 & light rain \\
\hline 625 & 2000 & $8+$ & light rain \\
\hline 626 & 4000 & 5 & light snow \\
\hline
\end{tabular}


Weather Combinations: Route 3-San Juan Pueblo Airport to Las Vegas Airport.

\begin{tabular}{|c|c|c|c|}
\hline Scenario & Ceiling & Visibility & Precipitation \\
\hline 700 & 5000 & 5 & none \\
\hline 701 & 600 & 5 & freezing rain \\
\hline 702 & 3500 & 8 & moderate rain \\
\hline 703 & 900 & 1 & heavy snow \\
\hline 704 & 2000 & 0.5 & moderate rain \\
\hline 705 & 900 & 4 & heavy rain \\
\hline 706 & 4000 & $8+$ & none \\
\hline 707 & 600 & 3 & moderate snow \\
\hline 708 & 1800 & 7 & moderate rain \\
\hline 709 & 800 & 1 & rone \\
\hline 710 & 4000 & 0.5 & heavy snow \\
\hline 711 & 600 & 1 & moderate snow \\
\hline 712 & 4000 & 4 & light snow \\
\hline 713 & 3500 & 1 & light snow \\
\hline 714 & 1600 & 3 & heavy rain \\
\hline 715 & 2000 & $8+$ & light rain \\
\hline 716 & 2000 & 1.5 & none \\
\hline 717 & 1600 & 1 & freezing rain \\
\hline 718 & 600 & 8 & moderate rain \\
\hline 719 & 3500 & 3 & freezing rain \\
\hline 720 & 2000 & 5 & light snow \\
\hline 721 & 900 & 5 & light rain \\
\hline 722 & 900 & 8 & light rain \\
\hline 723 & 1600 & 3 & heavy snow \\
\hline 724 & 2000 & 4 & none \\
\hline 725 & 5000 & 1.5 & light rain \\
\hline 726 & 1800 & 5 & moderate rain \\
\hline
\end{tabular}




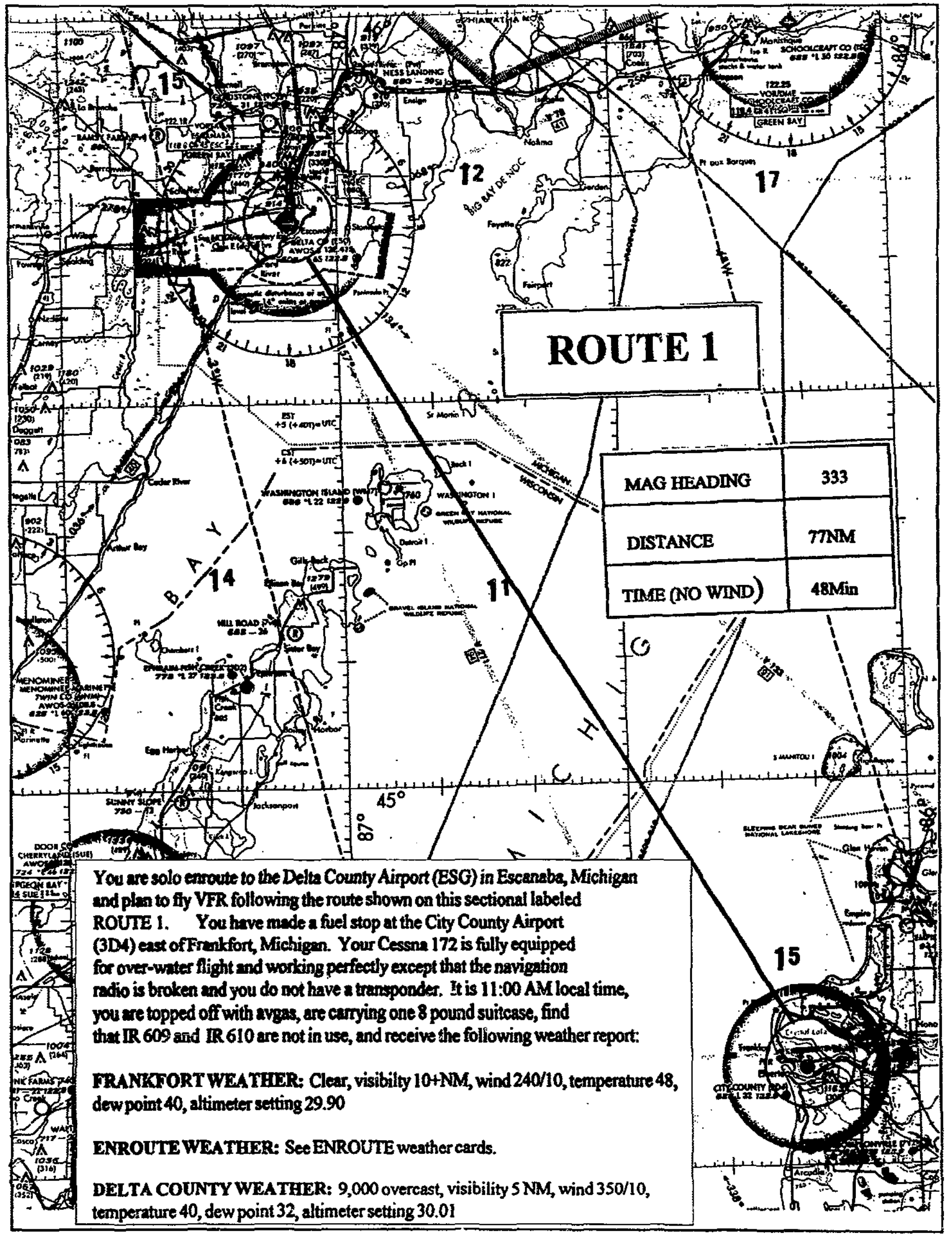




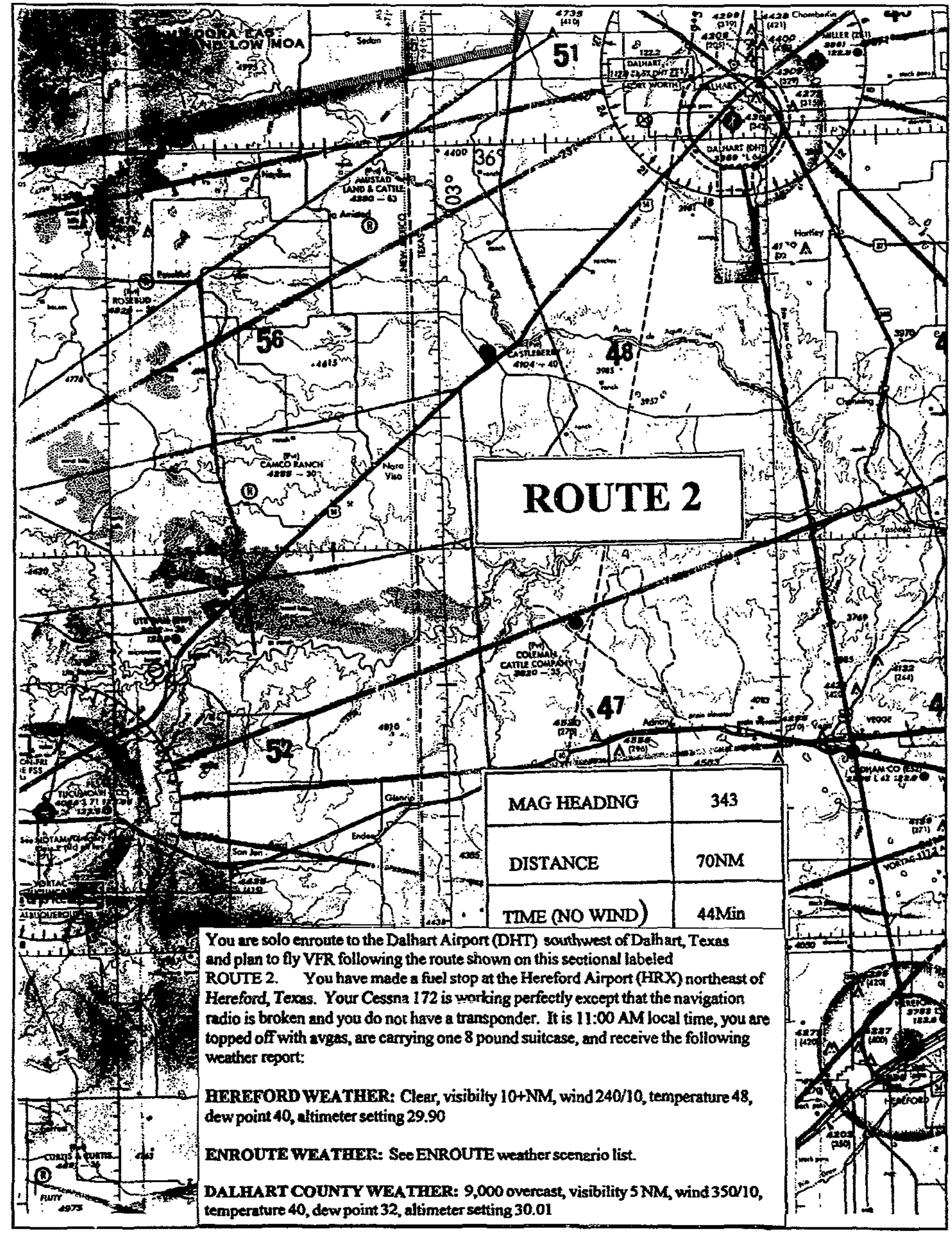




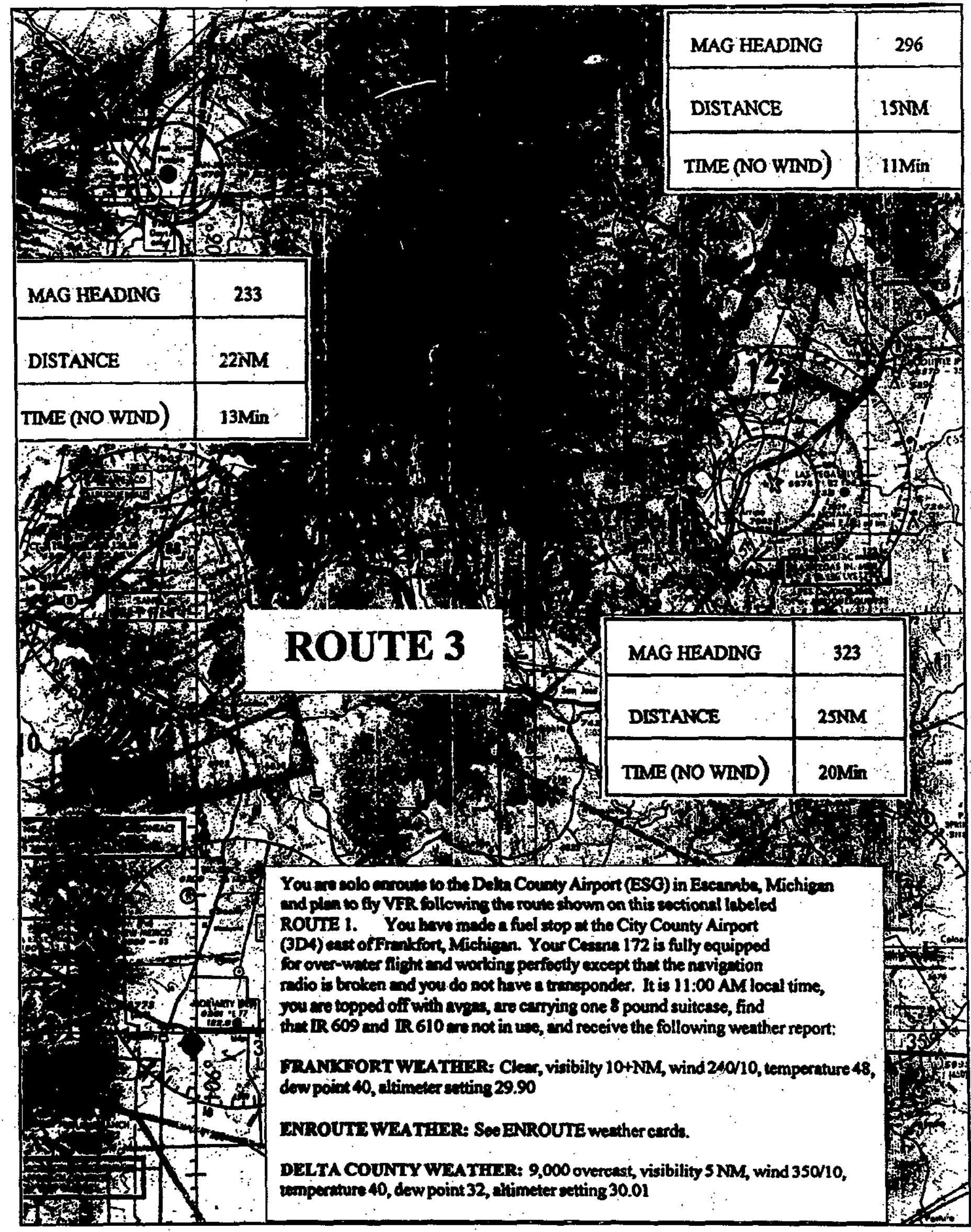


APPENDIX B

PILOT INFORMATION FORM 
Table B-1. Pilot Demographic information.

CERTIFICATES HELD:

Count Percsnt

Private Pilot

89

$59 \%$

Commercial Pilot $-23 \%$

Airline Transport Pilot

.

Certified Flight Instructor ----- 13

$8 \%$

Certified Flight Instructor

Instrument

24 $16 \%$

INSTRUMENT RATED:

Yes

83

$45 \%$

No $55 \%$

STATE OF RESIDENCE:

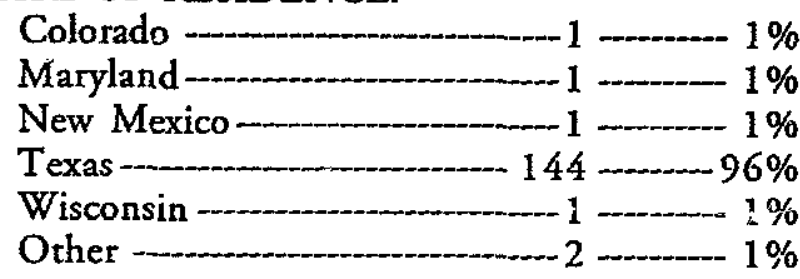

AGE':

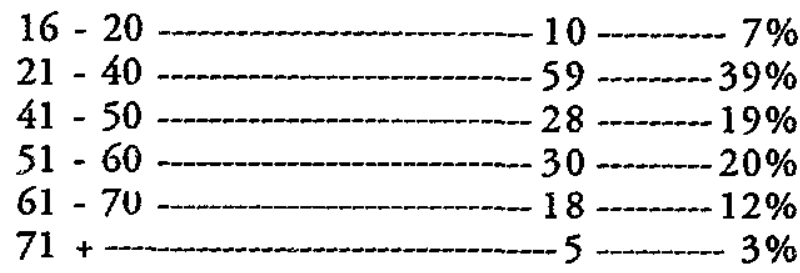

SEX:

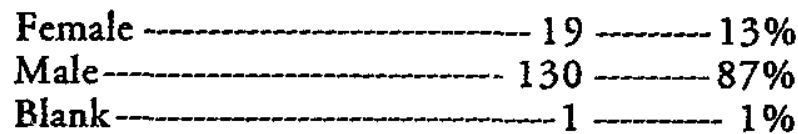

ENGINE RATING:

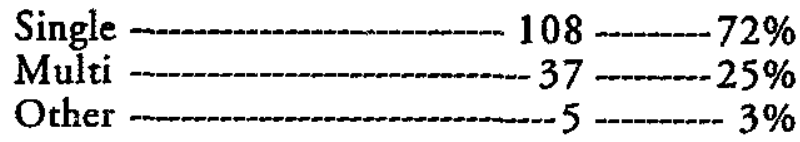

MEDICAL CERTIFICATE:

Class 1

Class 2

Class 3 $30-20 \%$ $49-33 \%$ $69-46 \%$

EVER BEEN A MILITARY PILOT?

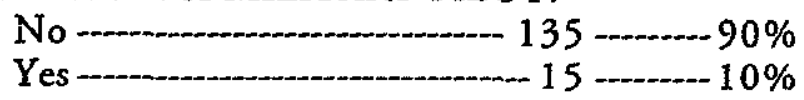

Note 1 : Age Mean $=42.64 ;$ S.D. $=15.44$
Table B-2. Flying Categories.

\section{Count Percent}

PERCENT OF FLYING AS:

PRIMARY JOB-EMPLOYED

AS A PILOT

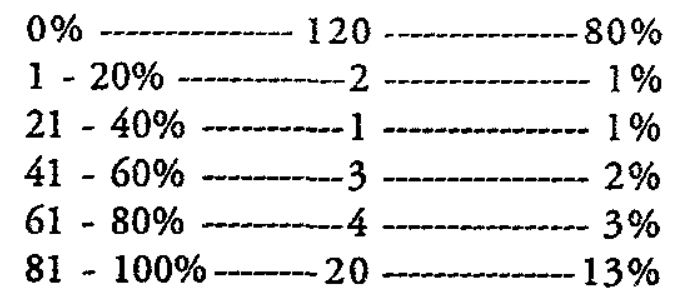

PERCENT OF FLYING AS: BUSINESS SUPPORTWORK RELATED

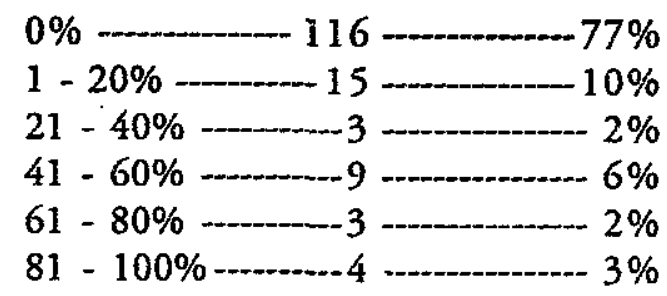

PERCENT OF FLYING AS:

PLEASURE

$0 \%-15$
$1-20 \%$
$21-40 \%$
$41-60 \%$


Table B-5. (Continued) ACTUAL INSTRUMENT HOURS

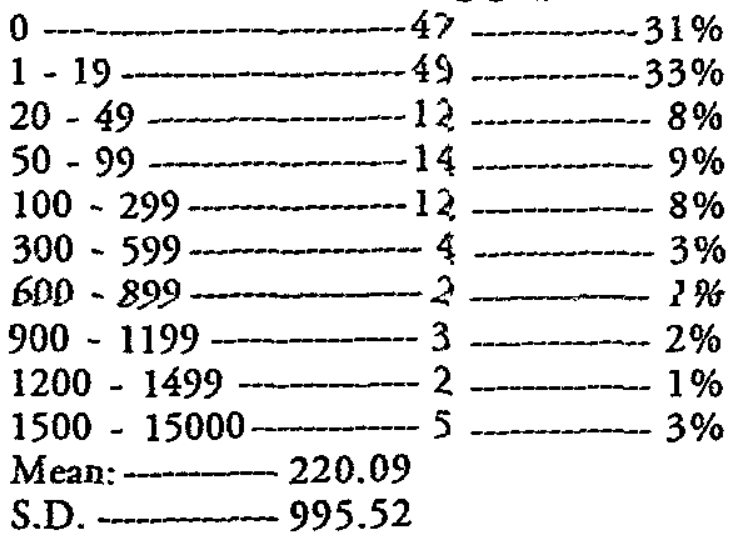

ACTUAL PLUS HOOD HOURS
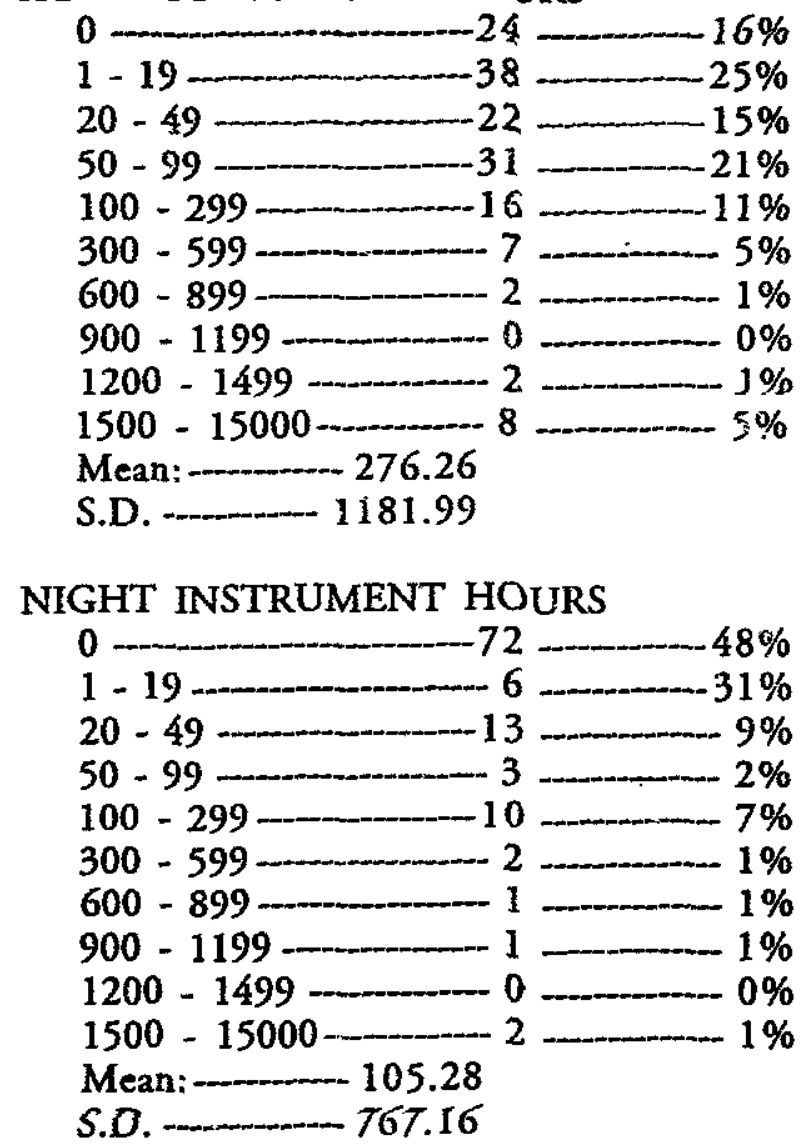

TOTAL INSTRUMENT APPROACHES FLOWN

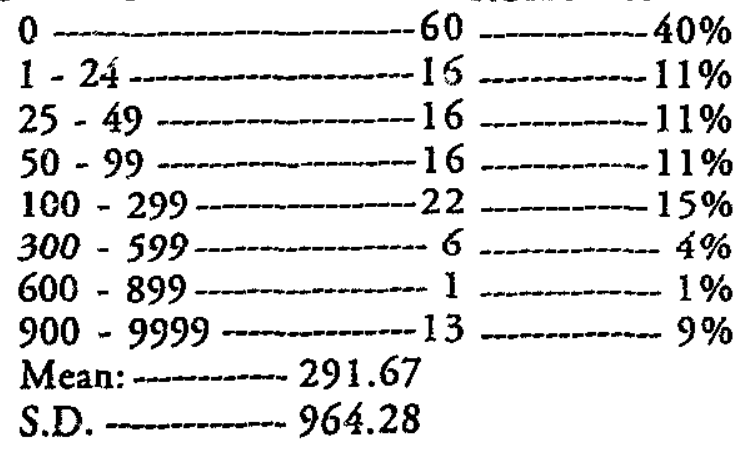

Table B-6. Flying Experience in the Last 90 Days.

TOTAL HOURS

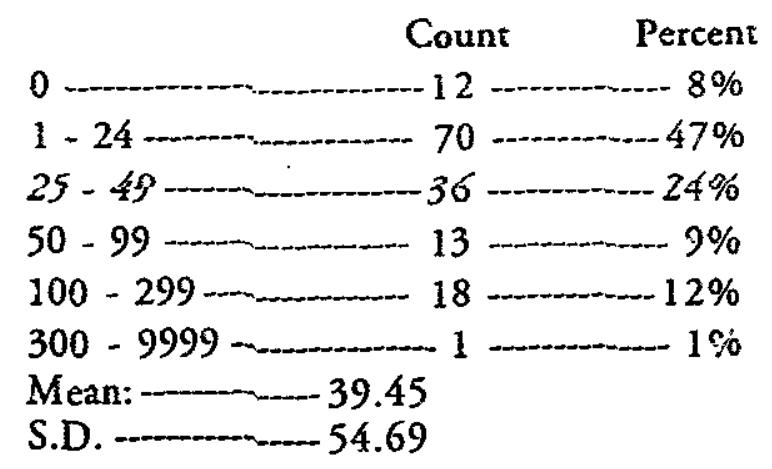

\section{DAY HOURS}

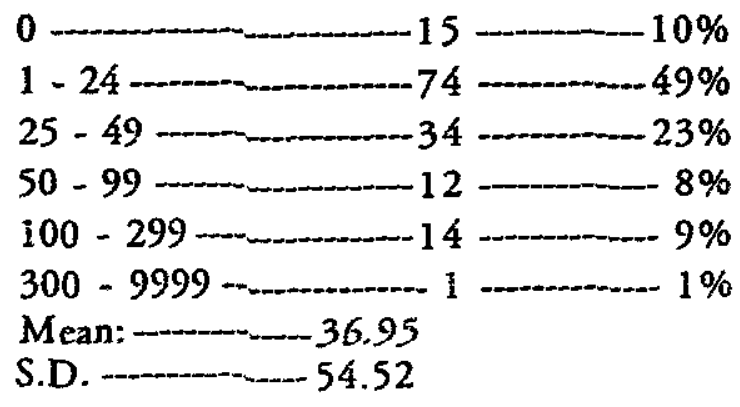

NIGHT HOURS

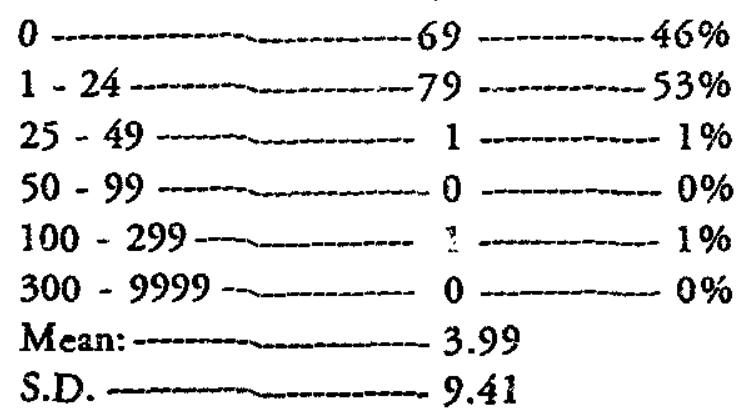

ACTUAL INSTRUMENT HOURS

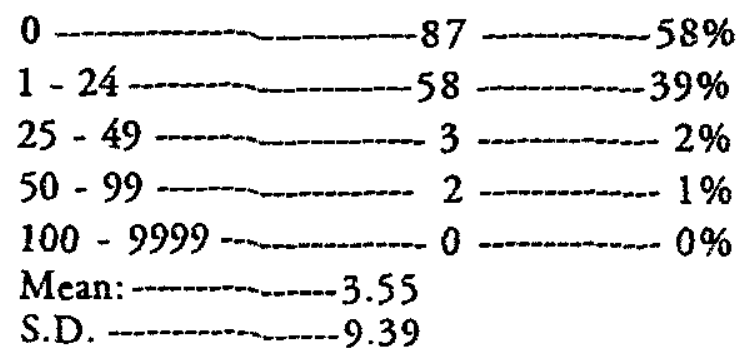


Table B-6. (Continued)

TOTAL INSTRUMENT HOURS

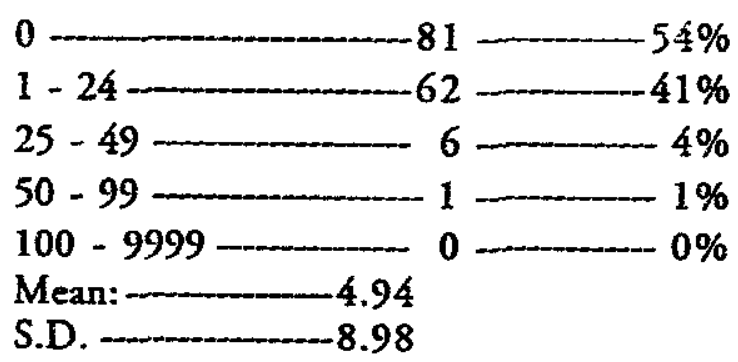

ACTUAL NIGHT INSTRUMENT HOURS

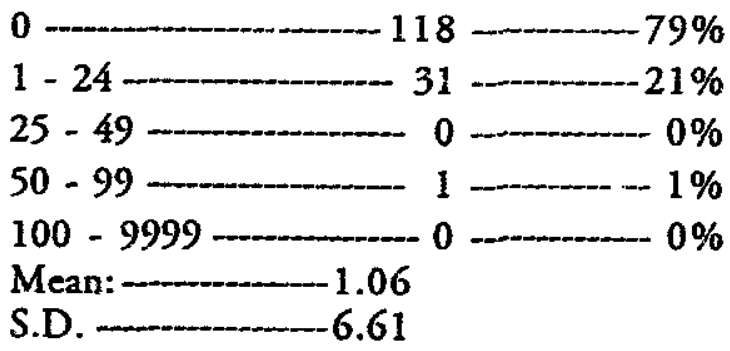

NUMBER OF INSTRUMENT APPROACHES FLOWN

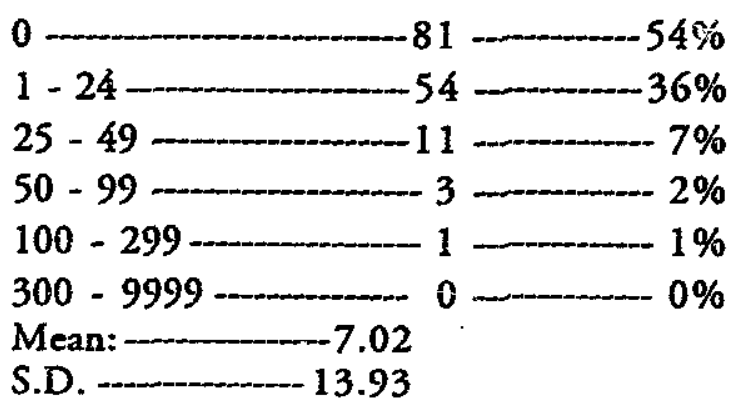

Table B-7. Characteristics of Aircraft Most Frequently Flown.

\section{NUMBER OF ENGINES}

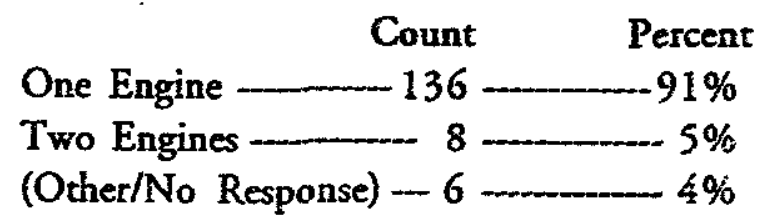

IFR CAPABLE?

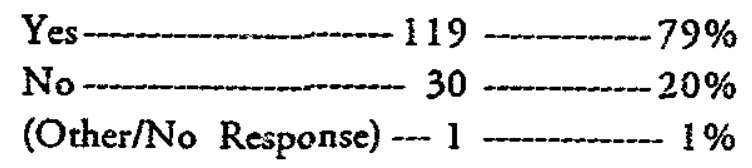

AUTO-PILOT EQUYPPED?

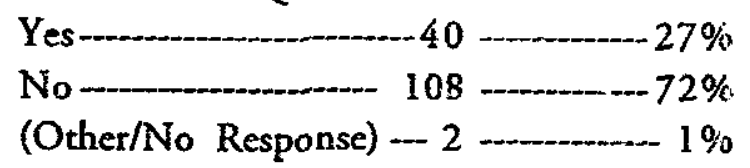

WEATHER RADAR EQUIPPED?

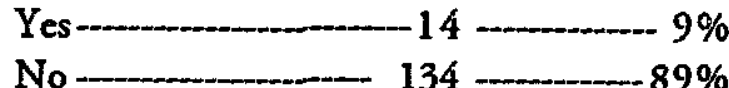

(Other/No Response) -- 2 - 2 1\%

TRANSPONDER EQUIPPED?

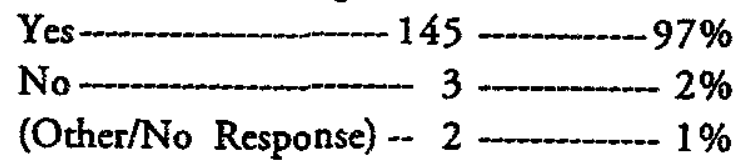

HOURS OF CRUISE CAPABLE

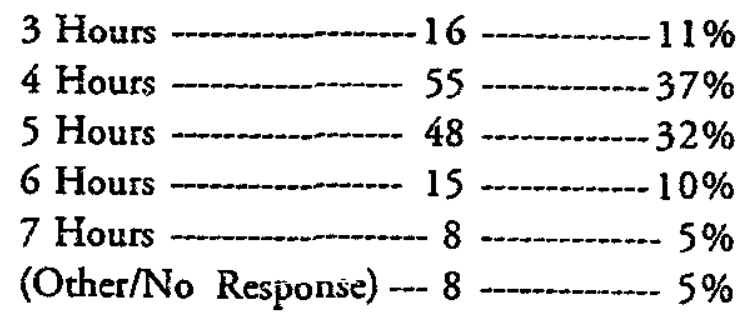

DO YOU OWN THIS AIRCRAFT?

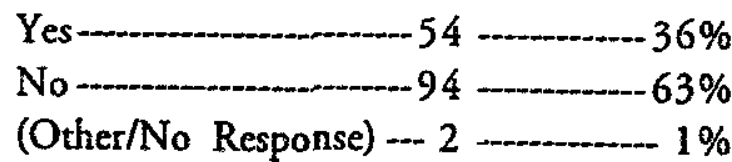


Table B-8. Attribute Experience - Terrain.

\section{FLOWN OVER IARGE BODY OF WATER}

I have NEVER flown into these or similar conditions
I have flown into these conditions ONCE or TWICE
I have flown into these conditions SEVERAL times $(3-5)$
I have flown into these conditions MANY times $(6-10)$
I have flown into these conditions NUMEROUS times $(11+)-198-19$

\section{FLOWN OVER NON-MOUNTAINOUS TERRAIN}

I have NEVER flown into these or similar conditions _._.

I have flown into these conditions ONCE or TWICE

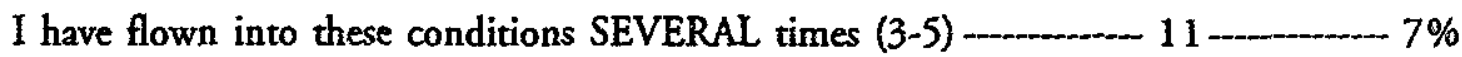

I have flown into these conditions MANY times (6-10) -..___ 11 \%

I have flown into these conditions NUMEROUS times (11+)

\section{FLOWN OVER MOUNTAINOUS TERRAIN}

I have NEVER flown into these or similar conditions _-_

$I$ have flown into these conditions ONCE or TWICE ___ 21 - $14 \%$

1 have flown into these conditions SEVERAL times (3-5) n... $22 \ldots$

1 have flown into these conditions MANY times $(6-10) \ldots$

I have flown into these conditions NUMEROUS times $(11+) \ldots 1$. $29 \ldots \ldots$

\section{Table B-9. Attribute experience - Precipitation}

\section{LIGHT RAIN}

I have NEVER flown into these or similar conditions
I have flown into these conditions ONCE or TWICE
I have flown into these conditions SEVERAL times $(3-5)$
I have flown into these conditions MANY times $(6-10)-3 \%$
I have flown into these conditions NUMEROUS tirses (11+)

\section{MODERATE RAIN}

I have NEVER flown into these or similar conditions _-_ 34

I have flown into these conditions ONCE or TWICE _.____ 51 _ $34 \%$

I have flown into these conditions SEVERAL times (3-5) $31 \ldots 21 \%$

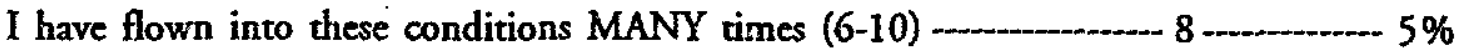

I have flown into these conditions NUMEROUS times (11+)

\section{HEAVY SNOW}

I have NEVER flown into these or similar conditions $81 \%$

I have flown into these conditions ONCE or TWICE

I have flown into these conditions SEVERAL times (3-5)

$I$ have flown into these conditions MANY times (6-10)

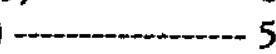

$6+3 \%$

$I$ haye flown into these conditions NUMEROUS times (11+) 
Table B-10. Attribute Experience - Visibility.

\section{ONE NAUTICAL MILE}

I have NEVER flown into these or similar conditions
I have flown into these conditions ONCE or TWICE
I have flown into these conditions SEVERAL times $(3-5)$
I have flown into these conditions MANY times $(6-10)$
I have flown into these conditions NUMEROUS times (11+)

FOUR NAUTICAL MILES

I have NEVER flown into these or similar conditions -

I have flown into these conditions ONCE or TWICE $\ldots 13 \%$

I have flown into these conditions SEVERAL times (3-5) -........ $24 \ldots$

I have flown into these conditions MANY times (6-10)

I have flown into these condirions NUMEROUS times (11+) - 57 -......-38\%

\section{EIGHT NAUTICAL MILES}

I have NEVER flown into these or similar conditions

I have flown into these conditions ONCE or TWICE

I have flown into these conditions SEVERAL times (3-5)

I have flown into these conditions MANY times (6-10)

I have flown into these conditions NUMEROUS times $\left(11_{+}\right) \ldots 1$ - $114 \ldots \ldots$

\section{Table B-11. Attribute experience - Ceiling}

\section{FEET}

\begin{tabular}{|c|c|}
\hline & Percent \\
\hline $\begin{array}{l}\text { I have NEVER flown into these or similar conditions } \\
\text { I have flown into these conditions ONCE or TWICE } \\
\text { I have flown into these conditions SEVERAL times }(3-5) \\
\text { I have flown into these conditions MANY times }(6-10) \\
\text { I have flown into these conditions NUMEROUS times (11+) }\end{array}$ & $\begin{array}{r}45-30 \\
38 \\
20 \\
20 \\
-11 \\
\end{array} 36$ \\
\hline
\end{tabular}

\section{FEET}

I have NEVER flown into these or similar conditions $-8-5 \%$

I have flown into these conditions ONCE or TWICE

I have flown into these conditions SEVERAL times (3-5)

$I$ have flown into these conditions MANY times (6-10)

I have flown into these conditions NUMEROUS times

\section{FEET}

I have NEVER flown into these or similar conditions ___

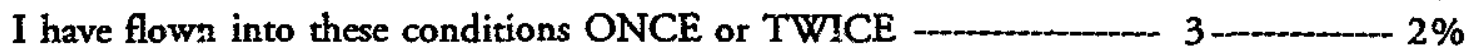

I have flown into these conditions SEVERAL times (3-5)

I have flown into these conditions MANY times (6-10)

I have flown into these conditions NUMEROUS times $(11+)$ 
APPENDIX C

EXPERT PILOT SAFETY RATINGS 


\section{EXPERT PILOT SAFETY RATINGS}

You have been selected as a Subject Matter Expert (SME) in the field of aviation safety due to your personal flying experience and/or your FAA job experience.

Place yourself in this scenario: Kelly (a new pilot VFR-only qualified with around 500 flying hours) asks you, "How safe would it be for me to fly this route VFR?"

Use this scale from 0 to 100 to indicate your expert safety assessment where:

$$
\begin{array}{lll}
0 & = & \text { Absolutely unsafe for Kelly to fly VFR. } \\
100= & \text { Totally safe for Kelly to fly VFR. }
\end{array}
$$

Note 1: Use your total experience (VFR and IMC) to evaluate the conditions on the following pages. NONE of the choices shown may deserve $a$ " $D$ " for "Absolutely unsafe" or a " 100 " for "Totally safe."

Use any numbers in the range from 0 to 100 to indicate your expert opinion, but you MAY NOT use the same number more than once on one page. If you feel that two choices are "Absolutely unsafe," rate one as " 0 " and the other as " 1 ".

You and we know that evaluating conditions for determining the safety of any flight involves interaction between all weather, aircraft, pilot and terrain variables. Yet each of us has developed benchmarks for certain values of each variable on which we make flight planning decisions. We ask you to consider each variable (i.e., TERRAIN, PRECIPITATION, VISIBILITY and CEILING) separately and give us your opinion on the relative safety of each value for VFR flying. Treat each page as a separate and unrelated rating assignment.

Read each of the following pages in turn, and give us your opirion on the safety of each value using the scale at the top of the page and using each number only once on each page.

Note 2: Values are not necessarily presented in order of "worst-to-best" or "bestto-worst." The order is simply to help us ensure that all target values are covered. Remember, you are evaluating each of the variables against the safety for a VFR qualified pilot with around 500 hours of flying time to fly in a reliable single engine VFR only aircraft.

\section{Turn the page and begin.}




\section{TERRAIN}

Rate each route on how safe you think it would be for a VFR only pilot with around 500 flying hours experience to encounter. Use the following scale and each number no more than once:

$\begin{array}{lll}0 & =\text { Absolutely unsafe } \\ 100= & \text { Totally safe }\end{array}$

ID Rating Destination

a. Route "1" (City County to Delta County, MI)

b. __ Route "2" (Hereford to Dalhart, TX)

c. Route "3" (Las Vegas to San Juan Pueblo, NM) 


\section{PRECIPITATION}

Rate each item on how safe you think it would be for a VFR only pilot with around $\mathbf{5 0 0}$ flying hours experience to encounter. Use the following scale and each number no more than once:
$0=$ Absolutely unsafe.
$100=$ Totally safe.
ID Rating Description
a. $\quad$ No Precipitation
b.
Light Rain
c.
Moderate Rain
d.
Heavy Rain
e.
Light Snow
f.
Moderate Snow
g.
Heavy Snow
h.
Freezing Rain 


\section{VISIBILITY}

Rate each item on how safe you think it would be for a VFR only pilot with around 500 flying hours experience to encounter. Use the following scale and each number no more than once:

$0=$ Absolutely unsaĩe.

$100=$ Totally safe.

ID Rating Description

a. $\quad 1 / 2 \mathrm{NM}$

b.

$1 \mathrm{NM}$

c.

$11 / 2$ NM

d.

2 NM

e.

$21 / 2 \mathrm{NM}$

f.

3 NM

g.

$4 \mathrm{NM}$

h.

$5 \mathrm{NM}$

I.

6 NM

j.

$7 \mathrm{NM}$

k.

8 NM

I.

More than $8 \mathrm{NM}$ 


\section{CEILING}

Rate each item on how safe you think it would be for a VFR only pilot with around $\mathbf{5 0 0}$ flying hours experience to encounter. Use the following scale and each number no more than once:

\begin{tabular}{|c|c|c|}
\hline $\begin{array}{l}0 \\
100\end{array}$ & $\begin{array}{l}= \\
=\end{array}$ & $\begin{array}{l}\text { utely unsafe. } \\
\text { y safe. }\end{array}$ \\
\hline ID & Rating & Description \\
\hline a. & & $600 \mathrm{ft}$. \\
\hline b. & & $700 \mathrm{ft}$. \\
\hline c. & & $800 \mathrm{ft}$. \\
\hline d. & & $900 \mathrm{ft}$. \\
\hline e. & & $1000 \mathrm{ft}$. \\
\hline f. & & $1200 \mathrm{ft}$ \\
\hline g. & & $1400 \mathrm{ft}$ \\
\hline h. & & $1600 \mathrm{ft}$ \\
\hline i. & & $1800 \mathrm{ft}$. \\
\hline j. & & $2000 \mathrm{ft}$ \\
\hline k. & & $2500 \mathrm{ft}$. \\
\hline I. & & \\
\hline $\mathrm{m}$. & & $3500 \mathrm{ft}$. \\
\hline n. & & $4000 \mathrm{ft}$. \\
\hline o. & & $5000 \mathrm{ft}$. \\
\hline & & over $5000 \mathrm{ft}$ \\
\hline
\end{tabular}




\section{Personal Experience Profile}

Thank you for your expert ratings. Your data will be combined with data from other experts to form the foundation for studying safety judgment of General Aviation (GA) pilots.

Now, please fill out the PILOT INFORMATION and four EXPERIENCE Forms which ask for your personal flying history. These forms are intended only for use in this study of GA pilots. Notice neither your name nor any personal identifying information is requested.

Please feel free to write suggestions or comments on these sheets regarding problems we may expect within the GA community with these forms.

The PILOT INFORMATION sheet requests personal flying history information which may be important in explaining the decision making process used by different subgioups within the GA pilot community.

The ATTRIBUTE EXPERIENCE forms appear similar to the four rating sheets you just completed. Instead of rating "HOW SAFE?" you are asked to indicate how much expeilence you have had under specific conditions. Because these forms are designed for the GA pilot community, you, as a senior expert, may well be responding level " 5 " to all these items -- and that is OK.

Here is the scale used on all four Attribute Experience forms:

$0=1$ have NEVER flown into these or highly similar conditions.

$1=$ I have flow into these conditions ONCE or TWICE

$2=$ (same as above)

$3=1$ have flown into these conditions SELERAL times.

$4=$ (same as above)

$5=$ I have flown into these conditions MANY times. 


\section{EXPERIENCE: TERRAIN}

How much personal expeience (VFR and IMC) do you have with these conditions:

$0=$ I have NEVER flown into these or highly similar conditions.

$1=1$ have flow into these conditions ONCE or TWICE

$2=$ (same as above)

$3=1$ have flown into these conditions SEVERAL times.

$4=$ (same as above)

$5=$ I have flown into these conditions MANY times.

ID Exper. Destination

a. Route "1" (City County to Delta County, MI)

b. Route "2" (Hereford to Dalhart, TX)

c. Route "3" (Las Vegas to San Juan Pueblo, NM) 


\section{EXPERIENCE: PRECIPITATION}

How much personal expeience (VFR and IMC) do you have with these conditions:

$0=$ I have NEVER flown into these or highly similar conditions.

1 = I have flow into these conditions ONCE or TWICE

$2=$ (same as above)

$3=1$ have flown into these conditions SEVERAL times.

$4=$ (same as above)

$5=1$ have flown into these conditions MANY times.

ID Exper. Description

a. No Precipitation

b.

Light Rain

c.

Moderate Rain

d.

Heavy Rain

e.

Light Snow

f.

Moderate Snow

g.

Heavy Snow

h.

Freezing Rain 


\section{EXPERIENCE: VISIBILILTY}

How much personal expeience (VFR and IMC) do you have with these conditions:

$0=I$ have NEVER flown into these or highly similar conditions.

$1=$ I have flow into these conditions ONCE or TWICE

$2=$ (same as above)

$3=1$ have flown into these conditions SEVERAL times.

$4=$ (same as above)

$5=1$ have flown into these conditions MANY times.

ID Exper. Description

a.

$1 / 2 \mathrm{NM}$

b.

1 NM

c.

$11 / 2 \mathrm{NM}$

d.

2 NM

e.

$21 / 2$ NM

f.

3 NM

g.

$4 \mathrm{NM}$

h.

$5 \mathrm{NM}$

I.

$6 \mathrm{NM}$

j.

$7 \mathrm{NM}$

k.

$8 \mathrm{NM}$

I.

More than $8 \mathrm{NM}$ 


\section{EXPERIENCE: CEILING}

How much personal expeience (VFR and IMC) do you have with these conditions:

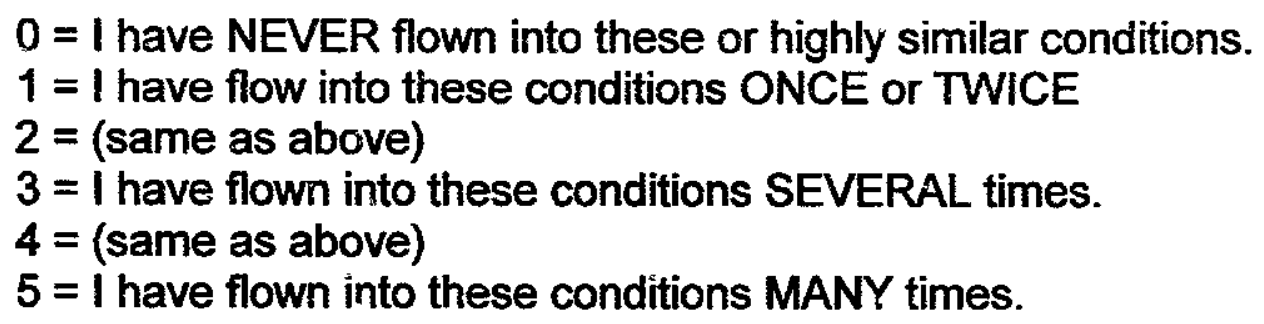

ID Exper. Description

a.

$600 \mathrm{ft}$.

b.

$700 \mathrm{ft}$.

c.

$800 \mathrm{ft}$.

d.

$900 \mathrm{ft}$.

e.

$1000 \mathrm{ft}$.

f.

$1200 \mathrm{ft}$.

g.

$1400 \mathrm{ft}$.

h.

$1600 \mathrm{ft}$.

i.

$1800 \mathrm{ft}$.

j.

$2000 \mathrm{ft}$.

k.

$2500 \mathrm{ft}$

I.

$3000 \mathrm{ft}$.

m.

$3500 \mathrm{ft}$.

n.

$4000 \mathrm{ft}$.

o.

$5000 \mathrm{ft}$.

p.

over $5000 \mathrm{ft}$ 
APPENDIX D

PLOTS OF EXPERT PILOT SAFETY RATINGS 
Safety Ratings of Precipitation by Expert Pilots

None

Light Rain

Light Snow'

Moderate Rain

Moderate Snow

Heavy Rain

Heavy Snow

Freezing Rain

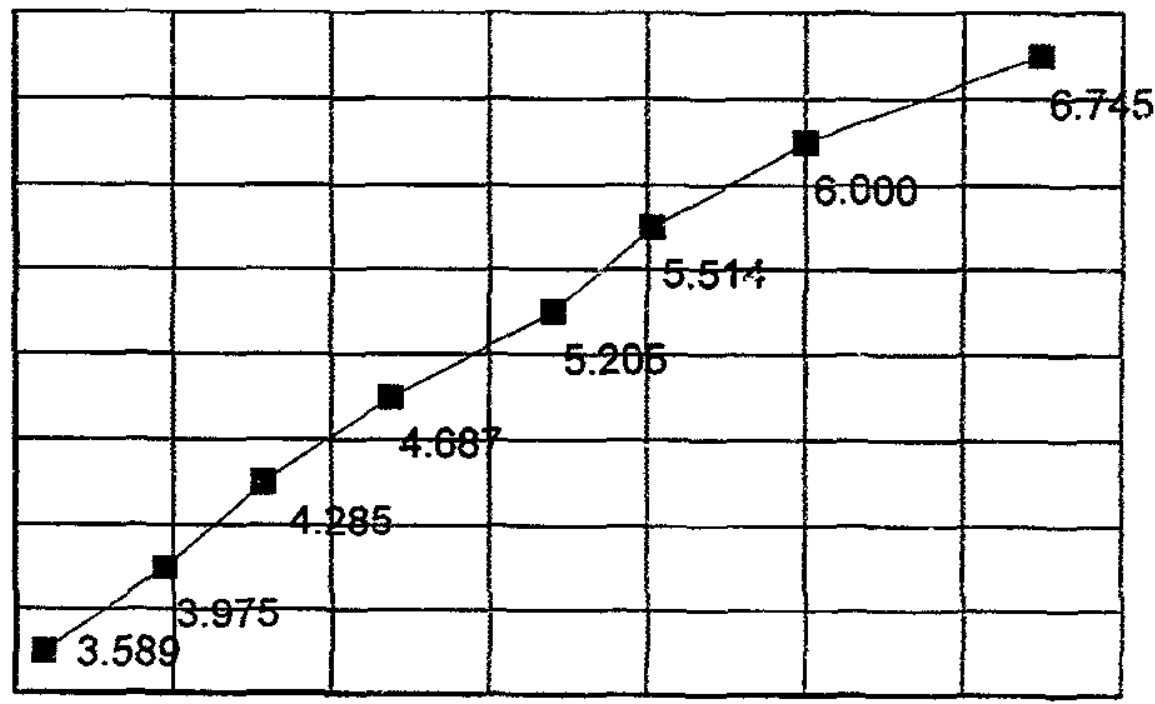
3.54
4.55
5.56
6.57
Safety Rating

Safety Ratings of Terrain by Expert Pilots

Flat Terrain

Over Water

Mountainous

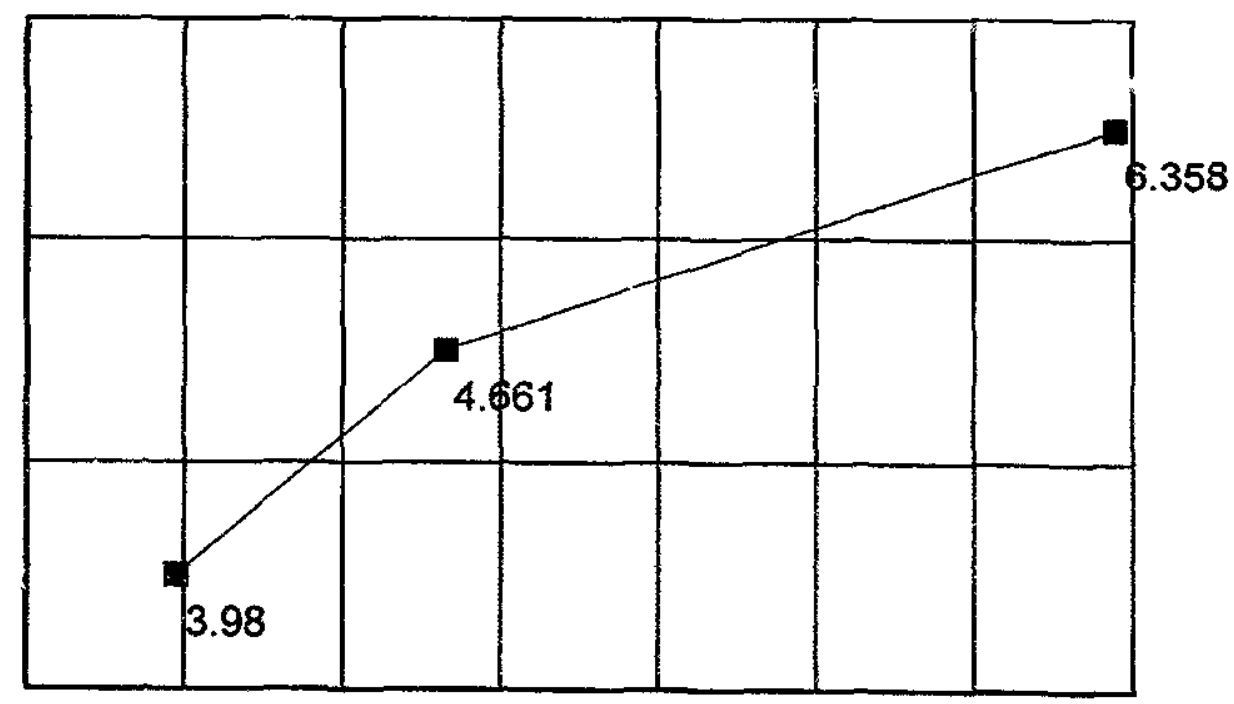

3.6

4

4.4

4.8

5.2

5.6

6

6.4

Safety Rating 
Safety Ratings of Visibility by Expert Pilots

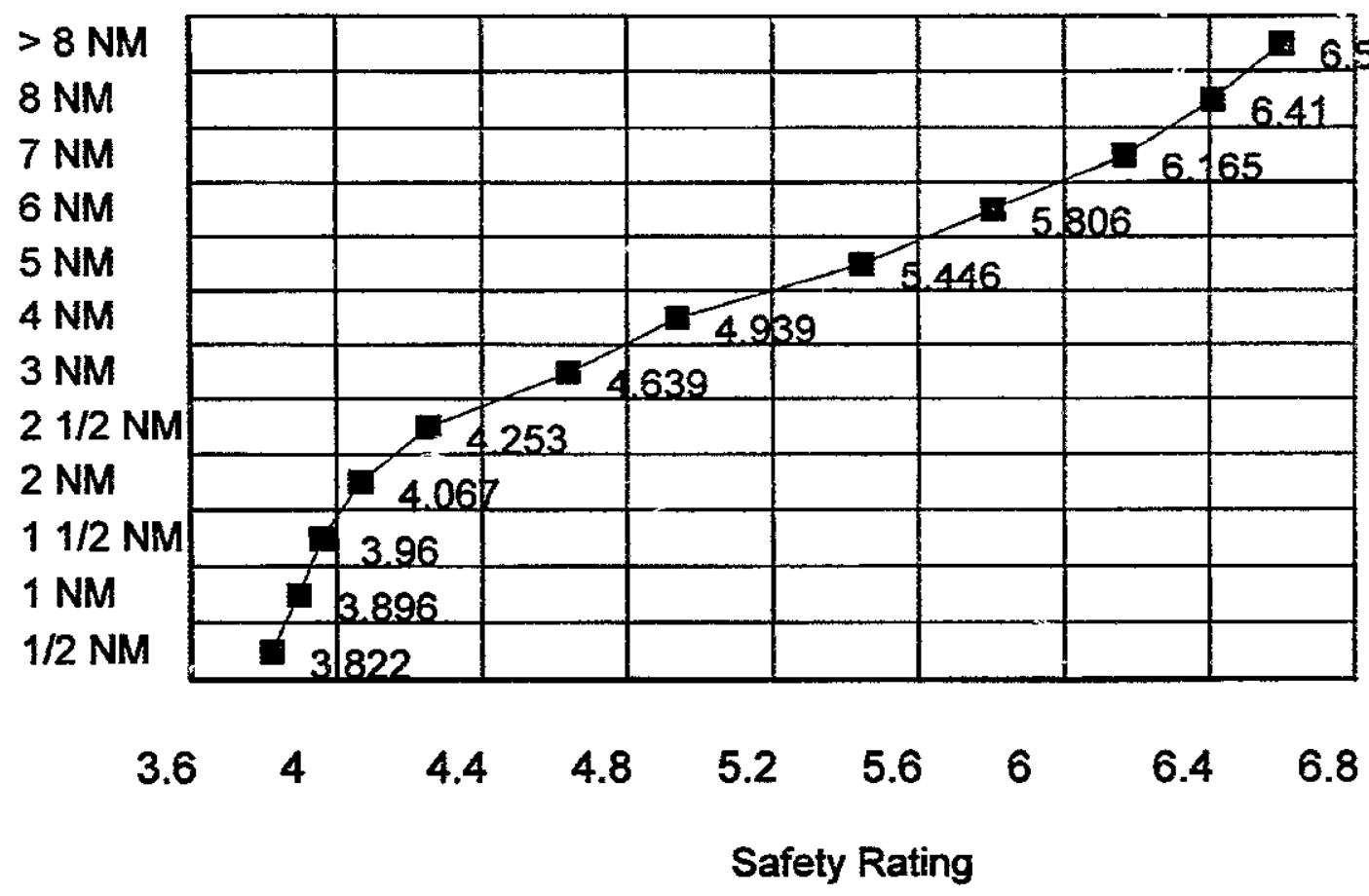

Safety Ratings of Ceiling by Expert Pilots

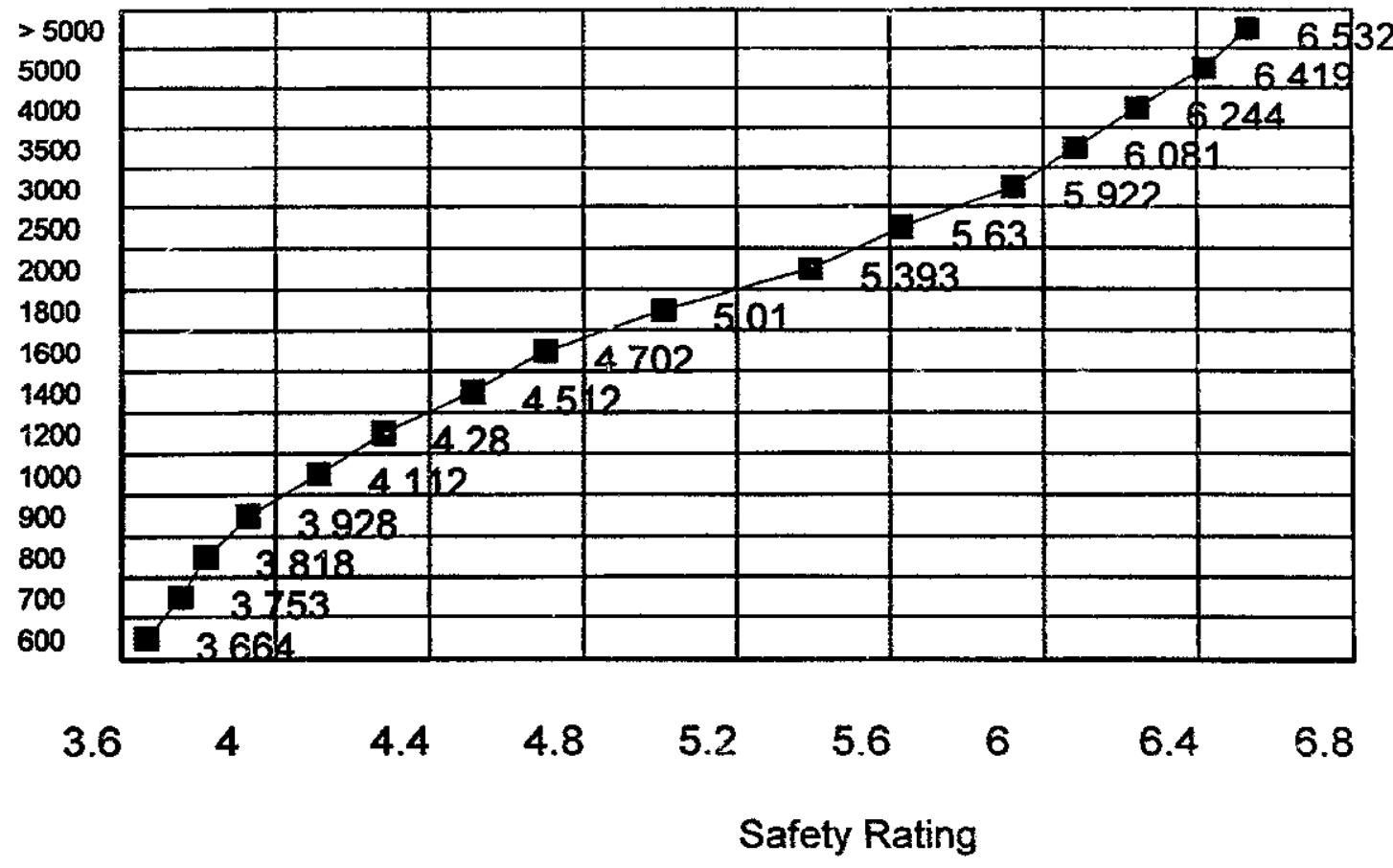

For all ratings, Mean $=5.00 ;$ Standard Deviation $=1.00$ 


\section{APPENDIX E \\ SELECTED PAIR COMPARISONS AMONG POLICY GROUPS FOR EACH SCENARIO}

(All mean differences statistically significant for $\mathrm{p}<.05$ ) 
Highlights of Characteristics for Mountainous Terrain Groups:

\begin{tabular}{|c|c|c|}
\hline GP1 & S-N: & Senior-Nominal Policy Group: (Mountainous) \\
\hline $\mathrm{S}-\mathrm{N}$ & $\mathrm{J}-\mathrm{N}$ & Compared to the Junior-Nominal group, this Senior-Nominal group has: \\
\hline 51 & 41 & Higher average Age \\
\hline $36 \%$ & $59 \%$ & Lower percentage report FP as highest certification \\
\hline S-N & J-B & Compared to the Junior-Bold group, this Senior-Nominal group has: \\
\hline 51 & 34 & Higher average Age \\
\hline 2.63 & 1.19 & Higher experience with Ceiling 800 FT \\
\hline 3.50 & 2.52 & Higher experience with Ceiling $1800 \mathrm{FT}$ \\
\hline $36 \%$ & $68 \%$ & Lower percentage report $\mathrm{PP}$ as highest certification \\
\hline 2.00 & 1.19 & Higher experience with Precip Moderate Rain \\
\hline $43 \%$ & $16 \%$ & Higher percentage own aircraft \\
\hline 1969 & 561 & Higher average Total Hours Flown \\
\hline S-N & S-C & Compared to the Senior-Cautious group, this Senior-Nominal group has: \\
\hline .83 & .60 & Higher average R-Squared (Use of Expert Info) \\
\hline 47 & 21 & Higher average Hours Flown Last 90 days \\
\hline 3.50 & 2.50 & Higher experience with Ceiling $1800 \mathrm{FT}$ \\
\hline 36 & 17 & Higher average Comfort Level \\
\hline 3.14 & 2.25 & Higher experience with Visibility $4 \mathrm{NM}$ \\
\hline 3.86 & 3.28 & Higher experience with Ceiling 4000 FT \\
\hline $66 \%$ & $86 \%$ & Lower percentage fly for Pleasure \\
\hline $36 \%$ & $61 \%$ & Lower percentage report $\mathrm{PP}$ as highest certification \\
\hline $2.4 \hat{\jmath}$ & 1.58 & Higher experience with Ceiling 800 FT \\
\hline GP2 & J-N: & Junior-Nominal Policy Group: (Mountainous) \\
\hline $\mathrm{J}-\mathrm{N}$ & S-N & Compared to the Senior-Nominal group, this Junior-Nominal group has: \\
\hline 41 & 51 & Lower average Age \\
\hline $59 \%$ & $36 \%$ & Higher percentage report $\mathrm{PP}$ as highest certification \\
\hline $\mathrm{J}-\mathrm{N}$ & J-B & Compared to the Junior-Bold group, this Junior-Nominal group has: \\
\hline 29 & 46 & Lower average Comfort Level \\
\hline 41 & 34 & Higher average Age \\
\hline $39 \%$ & $16 \%$ & Higher percentage own aircraft \\
\hline 3.10 & 2.52 & Higher experience with Ceiling 1800 FT \\
\hline $10 \%$ & $6 \%$ & Higher percentage Female \\
\hline 1963 & 561 & Higher average Total Hours Flown \\
\hline 1.81 & 1.19 & Higher experience with Precip Moderate Rain \\
\hline 1.84 & 1.19 & Higher experience with Ceiling 800 FT \\
\hline 2.59 & 2.10 & Higher experience with Precip Light Rain \\
\hline 1.90 & 1.35 & Higher experience with Visibility $1 \mathrm{NM}$ \\
\hline $33 \%$ & $16 \%$ & Higher percentage report COM/ATP as highest cert. \\
\hline .80 & .75 & Higher average R-Squared (Use of Expert Info) \\
\hline
\end{tabular}




\begin{tabular}{|c|c|c|}
\hline $\mathrm{J}-\mathrm{N}$ & S-C & Compared to the Senior-Cautious group, this Junior-Nominal group has: \\
\hline 29 & 17 & Higher average Comfort Level \\
\hline .80 & .60 & Higher average R-Squared (Use of Expert Info) \\
\hline $62 \%$ & $86 \%$ & Lower percentage flying for Pleasure \\
\hline 3.72 & 3.28 & Higher experience with Visibility $8 \mathrm{NM}$ \\
\hline 3.77 & 3.28 & Higher experience with Ceiling 4000 FT \\
\hline $22 \%$ & $5 \%$ & Higher percentage Primary Job as Pilot \\
\hline 49 & 21 & Higher average Hours Flown Last 90 days \\
\hline 2.94 & 2.25 & Higher experience with Visibility $4 \mathrm{NM}$ \\
\hline 3.10 & 2.50 & Higher experience with Ceiling $1800 \mathrm{FT}$ \\
\hline 41 & 48 & Lower average Age \\
\hline 1.90 & 1.39 & Higher experience with Visibility $1 \mathrm{NM}$ \\
\hline GP3 & J-B: & Junior-Bold Policy Group: (Mountainous) \\
\hline $\mathrm{J}-\mathrm{B}$ & S-N & Compared to the Senior-Nominal group, this Junior-Bold group has: \\
\hline 34 & 47 & Lower average Age \\
\hline 1.19 & 2.43 & Lower experience with Ceiling 800 FT \\
\hline 2.52 & 3.50 & Lower experience with Ceiling 1800 FT \\
\hline $16 \%$ & $36 \%$ & Lower percentage report COM/ATP as highest cert. \\
\hline $68 \%$ & $36 \%$ & Higher percentage report $\mathrm{PP}$ as highest certification \\
\hline 1.19 & 2.00 & Lower experience with Precip Moderate Rain \\
\hline $16 \%$ & $43 \%$ & Lower percentage Own Airrcraft \\
\hline 561 & 1969 & Lower average Total Flying Hours \\
\hline J-B & $\mathrm{J}-\mathrm{N}$ & Compared to the Junior-Nominal group, this Junior-Bold group has: \\
\hline 46 & 29 & Higher average Comfort Level \\
\hline $16 \%$ & $39 \%$ & Lower percentage Own Aircraft \\
\hline 34 & 41 & Lower average Age \\
\hline 2.52 & 3.10 & Lower experience with Ceiling $1800 \mathrm{FT}$ \\
\hline 561 & 1963 & Lower average Total Flying Hours \\
\hline 1.19 & 1.81 & Lower experience with Precip Moderate Rain \\
\hline 1.19 & 1.84 & Lower experience with Ceiling 800 FT \\
\hline 2.10 & 2.59 & Lower experience with Precip Light Rain \\
\hline 1.35 & 1.90 & Lower experience with Visibility $1 \mathrm{NM}$ \\
\hline $16 \%$ & $33 \%$ & Lower percentage report COM/ATP as highest cert. \\
\hline .75 & .80 & Lower average R-Squared (Use of Expert Info) \\
\hline J-B & S-C & Compared to the Senior-Cautious group, this Junior-Bold group has: \\
\hline 46 & 17 & Higher average Comfort Level \\
\hline 34 & 48 & Lower average Age \\
\hline $16 \%$ & $44 \%$ & Lower percentage Own Aircraft \\
\hline .75 & .60 & Higher average R-Squared (Use of Expert Info) \\
\hline $6 \%$ & $25 \%$ & Lower percentage Female \\
\hline $5 \%$ & $17 \%$ & Lower percentage use Weather Source: Other \\
\hline $16 \%$ & $33 \%$ & Lower percentage report COM/ATP as highest cert. \\
\hline 561 & 2140 & Lower average Total Flying Hours \\
\hline
\end{tabular}




\begin{tabular}{|c|c|c|}
\hline GP4 & S-C: & Senior-Cautious Policy Group: (Mountainous) \\
\hline $\mathrm{S}-\mathrm{C}$ & $S-N$ & Compared to the Senior-Nominal group, this Senior-Cautious group has: \\
\hline .60 & .83 & Lower average R-Squared (Use of Expert Info) \\
\hline 21 & 47 & Lower average Hours Flown Last 90 days \\
\hline 2.50 & 3.50 & Lower experience with Ceiling 1800 FT \\
\hline 17 & 36 & Lower average Comfort Level \\
\hline 2.25 & 3.14 & Lower experience with Visibility $4 \mathrm{NM}$ \\
\hline 3.28 & 3.86 & Lower experience with Ceiling 4000 FT \\
\hline $86 \%$ & $66 \%$ & Higher percentage flying for Pleasure \\
\hline $61 \%$ & $36 \%$ & Higher percentage report PP as highest certification \\
\hline 1.58 & 2.43 & Lower experience with Ceiling $800 \mathrm{FT}$ \\
\hline S-C & $\mathrm{J}-\mathrm{N}$ & Compared to the Junior-Nominal group, this Senior-Cautious group has: \\
\hline 17 & 29 & Lower average Comfort Level \\
\hline .60 & .80 & Lower average R-Squared (Use of Expert Info) \\
\hline $86 \%$ & $62 \%$ & Higher percentage flying for Pleasure \\
\hline 3.28 & 3.72 & Lower experience with Visibility $8 \mathrm{NM}$ \\
\hline 3.28 & 3.77 & Lower experience with Ceiling 4000 FT \\
\hline $5 \%$ & $22 \%$ & Lower percentage Primary Job as Pilot \\
\hline 21 & 49 & Lower average Hours Flown Last 90 days \\
\hline 2.25 & 2.94 & Lower experience with Visibility 4 NM \\
\hline 2.50 & 3.10 & Lower experience with Ceiling $1800 \mathrm{FT}$ \\
\hline $25 \%$ & $10 \%$ & Higher percentage Female \\
\hline 48 & 41 & Higher average fige \\
\hline 1.39 & 1.90 & Lower experience with Visibility I NM \\
\hline S-C & J-B & Compared to the Junior-Bold group, this Senior-Cautious group has: \\
\hline 17 & 46 & Lower average Comfort Level \\
\hline 48 & 34 & Highes average Age \\
\hline $44 \%$ & $16 \%$ & Higher percentage Own Aircraft \\
\hline .60 & .75 & Lower average R-Squared (Use of Expert Info) \\
\hline $25 \%$ & $6 \%$ & Higher percentage Female \\
\hline $17 \%$ & $5 \%$ & Higher percentage use Weather Source: Other \\
\hline $33 \%$ & $16 \%$ & Higher percentage report COM/ATP as highest cert. \\
\hline 2140 & 561 & Higher average Total Flying Hours \\
\hline \multicolumn{3}{|c|}{ Highlights of Characteristics for Over-Water Terrain Groups: } \\
\hline GP-A & $\mathrm{T}-\mathrm{N}:$ & Total-Nominal Policy Group: (Over Water) \\
\hline $\mathbf{T}-\mathbf{N}$ & T-B & Compared to the T-B group, this $\mathrm{T}-\mathrm{N}$ group has: \\
\hline 27 & 40 & Lower average Comfort Level \\
\hline $1 \%$ & $5 \%$ & Lower percentage use Weather Source: None \\
\hline 1.71 & 1.29 & Higher experience with Precip Moderate Rain \\
\hline GP-B & T-B: & Total-Bold Policy Group: (Over Water) \\
\hline T-B & $\mathbf{T}-\mathbf{N}$ & Compared to the $\mathrm{T}-\mathrm{N}$ group, this T-B group has: \\
\hline 40 & 27 & Higher average Comfort Level \\
\hline $5 \%$ & $1 \%$ & Higher percentage use Weather Source: None \\
\hline 1.29 & 1.71 & Lower experience with Precip Moderate Rain \\
\hline
\end{tabular}




\begin{abstract}
APPENDIX F
COMPREHENSIVE OCCUPATIONAL

DATA ANALYSIS PROGRAM (CODAP)
\end{abstract}




\section{Comprehensive Occupational Data Analysis Program (CODAP)}

CODAP is a suite of software products developed by the US Air Force for the analysis of large bodies of occupational data, commonly obtained from job analyses and other studies of elements of the Air Force personnel system. In addition to its use by the Air Force, CODAP has also been adopted for use by foreign and domestic governmental units, including the Australian government and the state of Maryland. One use of CODAP which is particularly relevant to the current study is its application in studies of promotion boards. The linear modeling capabilities of CODAP components allow for the identification of the werth functions used by promotion boards in the evaluation of individuals for promotion. This process, which is often termed "policy-capturing" allows for the explication of the relative weighting which the board and the constituent members have applied to the available demographic, training, performance, and other data which are provided for each individual eligible for promotion in arriving at their global promote versus do-not-promote decision. In some ways this is highly similar to the decision process undertaken by pilots in evaluating the many elements of weather information prior to making their go versus no-go decision. A similar technique (conjoint analysis) has been used in previous studies of aviator decision making (Flathers, Giffin, and Rockwell; 1982).

GRPREL: (pronounced "Group" "Rel") A standard interrater reliability program in the CODAP system. For a given list of items rated by a set of Subjec: Matter Experts (SMEs), this program reports two measures of interrater agreement $\left(R_{11}\right.$ and $\left.R_{k k}\right)$. The $R_{11}$ value indicates the reliabilitly of the observed set of ratings - while 0.10 is considered a minimum for usable rater agreement, a value of 0.20 or greater is desired. The $\mathbf{R}_{k k}$ value is driven by the number of raters acutally used. Although an $\mathbf{R}_{k k}$ of 0.90 is usually desired, it may not be practical in a particular study because of a small number of raters (SMEs) that may be subdivided even further into smaller groups based on policy differences. The GRPREL program also computes means and standard deviations for each item in the list. Item-level reports are printed in three orders: original sequence, ordered descending y mean value, and ordered descending on standard deviation. GRPREL computes each rater's correlation with the full-group mean vector and uses a probability evaluation to recommend the removal of deviant (non-cooperative or reversed scale) raters. The program can automatically iterate and remove flagged raters until either a sufficient level of agreement $\left(R_{k k}=0.90\right)$ is reached or no raters can be found with a probability (of deviant rating) above 0.95 .

An overview of the CODAP system is provided by Christal (1974), and a complete description of the interrater reliability components is given in Staley and Weissmuller (1981). The interested reader is directed to those sources for a more complete technical description of these software analytic tools. 